\title{
EFEITO DO LASER TERAPÊUTICO NA \\ CICATRIZAÇÃO TENDINOSA: \\ ESTUDO EXPERIMENTAL EM RATOS.
}

Marcelo Rodrigo Tavares

Dissertação apresentada ao programa de PósGraduação Interunidades Bioengenharia Escola de Engenharia de São Carlos/ Faculdade de Medicina de Ribeirão Preto/ Instituto de Química de São Carlos da Universidade de São Paulo, para obtenção do título de Mestre em Bioengenharia.

ORIENTADOR: Prof. Dr. Nilton Mazzer

Ribeirão Preto

2002 


\section{FICHA CATALOGRÁFICA}

\section{Preparada pela Biblioteca Central do Campus}

Administrativo de Ribeirão Preto / USP

Tavares, Marcelo Rodrigo

Efeito do laser terapêutico na cicatrização tendinosa: estudo experimental em ratos / Marcelo Rodrigo Tavares. -- Ribeirão Preto, 2002.

Dissertação (Mestrado). - Área Interunidades em Bioengenharia da EESC/FMRP/IQSC - Universidade de São Paulo, 2002.

Orientador: Prof. Dr. Nilton Mazzer

1. Cicatrização tendinosa. 2. Laser terapêutico 


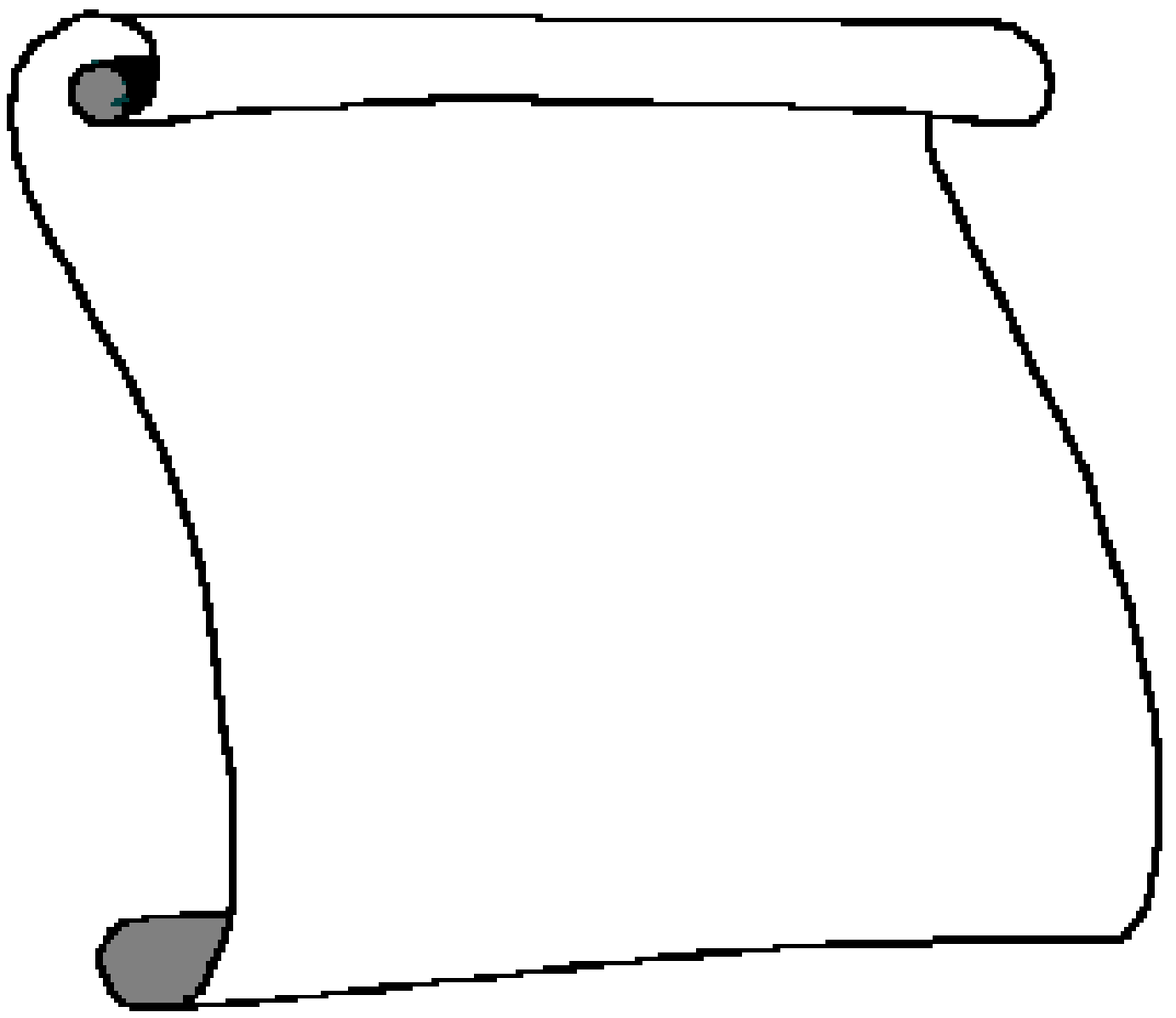

"O Eterno tudo criou sem exceção, só o Senhor será considerado justo.

Ele é o rei invencível que permanece para sempre.

Quem será capaz de relatar suas obras? Quem poderá compreender suas maravilhas? Quem poderá descrever todo poder de sua grandeza? Quem empreenderá a explicação de sua misericórdia? 


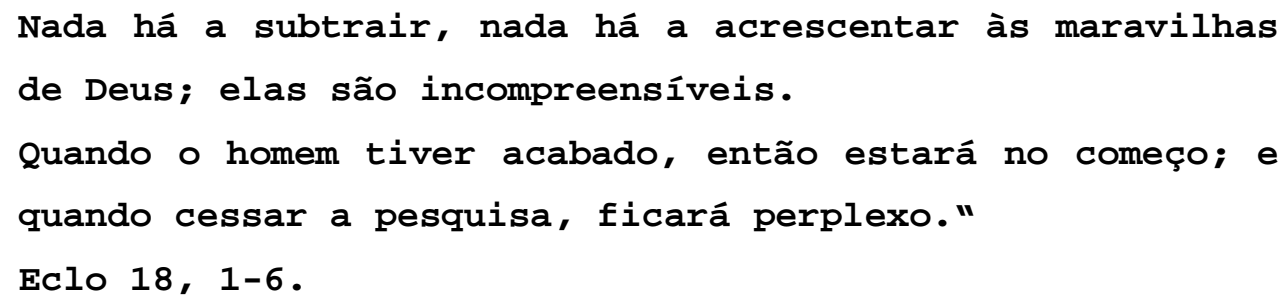

\section{AGRADECIMENTOS}

Ao meu orientador Prof. Dr. Nilton Mazzer, pela sua confiança, apoio, amizade e orientação para a elaboração deste trabalho.

À colega Dr. Mônica Pastorelo, pela dedicação e disponibilidade, que tanto contribuíram para realização deste trabalho.

À funcionária do serviço de patologia da FMRP - USP Auristela de Mello Martins, pelo companheirismo, atenção e por seus valiosos auxílios.

À fisioterapeuta e amiga Anadely Aparecida Silva, pelo auxílio e disponibilidade.

À direção e aos funcionários do Campus - Campo Belo UNIFENAS, pela atenção, empenho e dedicação.

Aos funcionários Francisco Carlos Mazzocato, Luiz Henrique Alves Pereira e Maria Teresinha de Moraes do Laboratório de Bioengenharia da Faculdade de Medicina de Ribeirão Preto da Universidade de São Paulo, pela solicitude e atenção.

À Prof. Giovana Elias Riboli Freire, pela atenção e ensinamentos. 


\section{SUMÁRIO}

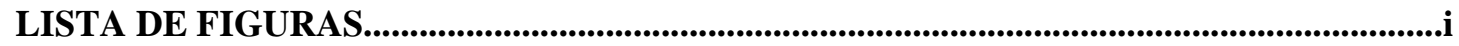

LISTA DE TABELAS.........................................................................................................ii

LISTA DE ABREVIATURAS E SIGLAS.......................................................................ii

LISTA DE SIMBOLOS.........................................................................................................

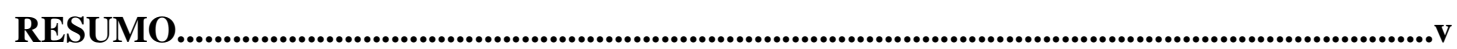

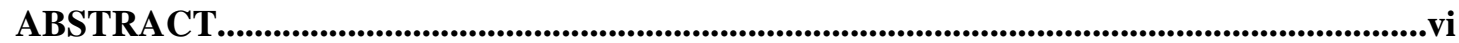

\section{INTRODUÇÃO}

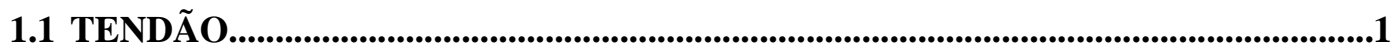

1.2 CICATRIZAÇÃO TENDINOSA........................................................................................2

1.3 O LASER TERAPÊUTICO...............................................................................................5

1.3.1 Definiçãa o......................................................................................................................................5

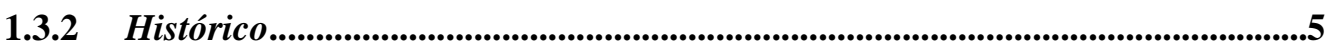

1.3.3 Classificação..............................................................................................................................6

1.3.4 Princípios Físicos da Radiação Laser..........................................................................6

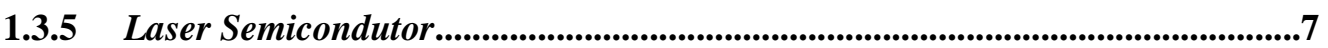

1.3.6 Características da Radiação Laser............................................................................8

1.3.7 O Laser de Arsenieto de Gálio ( AsGa) ...................................................................9

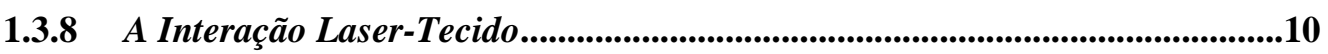

1.3.9 Efeitos Fisiológicos do Laser de Baixa Intensidade.........................................10

1.3.9.1 Efeitos Primários ou Diretos.....................................................................10 
1.3.9.1.1 Bioquímico.........................................................................................10

1.3.9.1.2 Bioelétrico..............................................................................................11

1.3.9.1.3 Bioenergético......................................................................................11

1.3.9.2 Efeitos Secundários ou Indiretos............................................................11

1.3.9.3 Efeitos Terapêuticos..................................................................................................11

1.3.9.3.1 Efeito Analgésico.....................................................................................12

1.3.9.3.2 Efeito Antiinflamatório.....................................................................12

1.3.9.3.3 Efeito Antiedematoso...........................................................................12

1.3.9.3.4 Efeito Cicatrizante.........................................................................13

1.3.10 Dosimetria..........................................................................................................................14

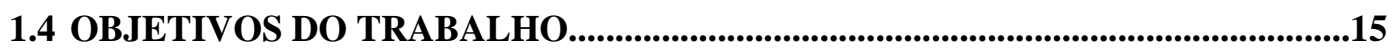

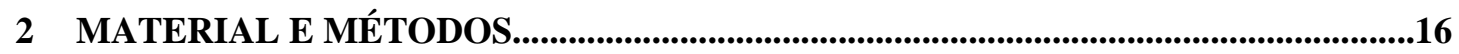

2.1 APARELHO DE LASER....................................................................................................16

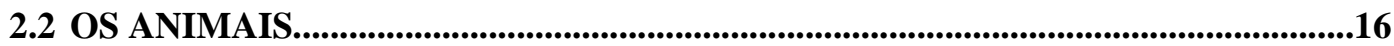

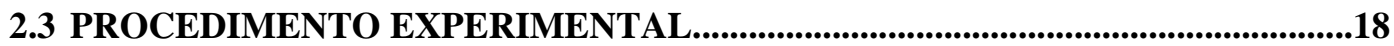

2.4 GRUPOS DE ANIMAIS.....................................................................................................18

2.5 O TRATAMENTO COM LASER................................................................................20

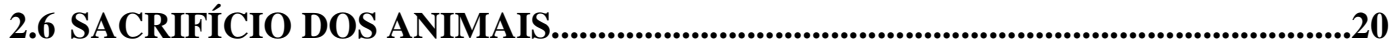

2.7 PREPARAÇÃO DAS LÂMINAS E ANÁLISE HISTOLÓGICA................................21

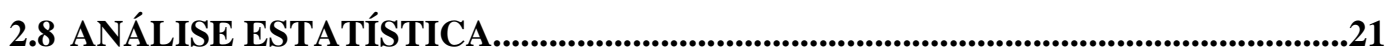

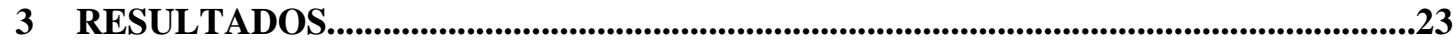

3.1 TESTE DE CONTRASTE DE MÉDIAS ENTRE OS GRUPOS TRATAMENTO E CONTROLE NOS DIFERENTES TEMPOS.............................................................23

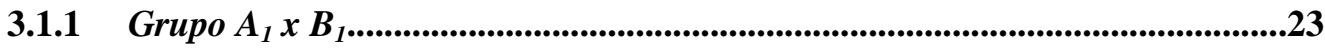


3.1.1.1 Presença de Células Inflamatórias.........................................................23

3.1.1.2 Vascularização...................................................................................................24

3.1.1.3 Presença de Fibroblasto...........................................................................................24

3.1.1.4 Presença de Colágeno................................................................................24

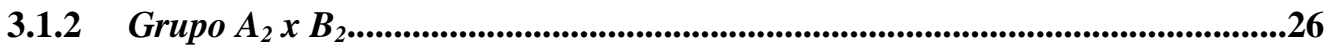

3.1.2.1 Presença de Células Inflamatórias...................................................................26

3.1.2.2 Vascularização.......................................................................................................27

3.1.2.3 Presença de Fibroblasto..........................................................................................27

3.1.2.4 Presença de Colágeno................................................................................................27

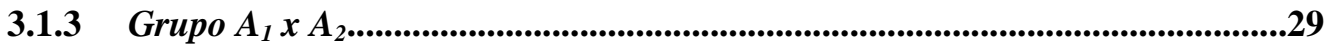

3.1.3.1 Presença de Células Inflamatórias..............................................................29

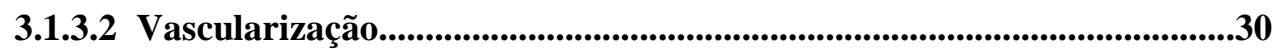

3.1.3.3 Presença de Fibroblasto.........................................................................................30

3.1.3.4 Presença de Colágeno..............................................................................................30

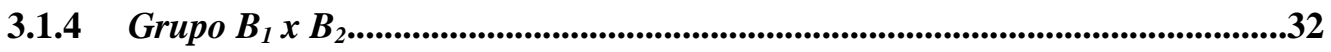

3.1.4.1 Presença de Células Inflamatórias...........................................................32

3.1.4.2 Vascularização.......................................................................................33

3.1.4.3 Presença de Fibroblasto......................................................................................33

3.1.4.4 Presença de Colágeno................................................................................33

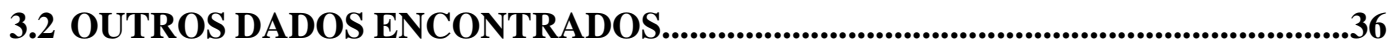

3.2.1 Presença de Células Gigantes...................................................................................36

3.2.2 Presença de Metaplasia Cartilaginosa.........................................................................36

3.2.3 Ausência de Necrose e/ou Calcificações................................................................36

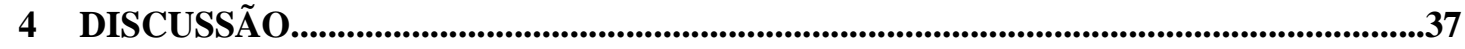

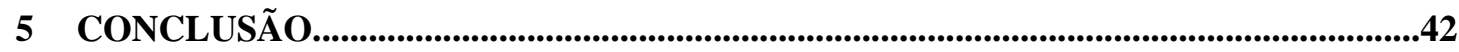




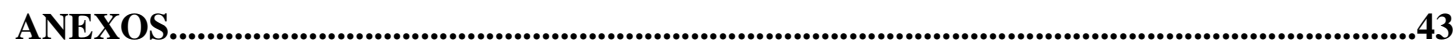

REFERÊNCIAS BIBLIOGRÁFICAS.........................................................................49 


\section{LISTA DE FIGURAS}

FIGURA 01 - Aparelho de laser utilizado para o tratamento..................................................17

FIGURA 02 - Caneta do laser AsGa 904nm.................................................................17

FIGURA 03 - Dissecação do tendão calcâneo................................................................................19

FIGURA 04 - Tenotomia do tendão calcâneo...............................................................................19

FIGURA 05 - Microscopia dos tendões calcâneos dos animais sacrificados no $8^{\circ}$ PO.........25

FIGURA 06 - Histograma demonstrando a comparação das médias entre os grupo A1 e B1

FIGURA 07 - Microscopia dos tendões calcâneos dos animais sacrificados no $15^{\circ}$ PO.......28

FIGURA 08 - Histograma demonstrando a comparação das médias entre os grupo A2 e

B2

FIGURA 09 - Microscopia dos tendões calcâneos dos animais tratados.................................31

FIGURA 10 - Histograma demonstrando a comparação das médias entre os grupo A1 e A2

FIGURA 11 - Microscopia dos tendões calcâneos dos animais controles.................................34

FIGURA 12 - Histograma demonstrando a comparação das médias entre os grupo B1 e B2 


\section{LISTA DE TABELAS}

TABELA 01 - Tabela demonstrando os grupos experimentais..................................................20

TABELA 02 - Resultados das médias nos grupos sacrificados no $8^{\circ}$ PO................................24

TABELA 03 - Resultados das médias nos grupos sacrificados no $15^{\circ}$ PO............................27

TABELA 04 - Resultados das médias nos grupos com exposição ao laser................................30

TABELA 05 - Resultados das médias nos grupos controle.............................................................33 
LISTA DE ABREVIATURAS E SIGLAS

ATP - Adenosina trifosfato

EESC - Escola de Engenharia de São Carlos

PO - Pós Operatório 


\section{LISTA DE SIMBOLOS}

$A^{0}$ - Unidade de medida em Ângstron

$\mathrm{Hz}$ - Unidade de medida da frequência

T - Período

Km/s - Kilômetros por segundo

W - Watts

mW - Miliwatts

J - Joule

HeNe - Hélio e Neônio

AsGa - Arsenieto e Gálio

AsGaAl - Arsenieto, Gálio e Alumínio mm - Milímetros

$\mathrm{J} / \mathrm{cm}^{2}$ - Joules por centímetro quadrado

ns - Nanosegundos

g - Gramas 


\section{RESUMO}

TAVARES, M. R. (2002). Efeito do laser terapêutico na cicatrização tendinosa: estudo experimental em ratos. Ribeirão Preto, 2002. p. Dissertação (Mestrado) - Escola de Engenharia de São Carlos/ Faculdade de Medicina de Ribeirão Preto, Universidade de São Paulo.

A terapia a laser de baixa potência vem sendo utilizada para minimizar os efeitos maléficos da inflamação, bem como para acelerar a cicatrização dos tecidos lesados. Este estudo, visa observar as alterações causadas pela irradiação do laser diodo arsenieto de gálio (904nm), no tendão calcâneo em ratos. Foram utilizados 30 ratos da linhagem Wistar, com peso médio de $235 \mathrm{~g}$, divididos em dois grupos, um com 20 e outro com 10 animais. Todos os animais foram submetidos a tenotomia do tendão calcâneo direito. $\mathrm{O}$ tratamento com laser foi iniciado após 24 horas em um dos grupos, com a dose de $4 \mathrm{~J} / \mathrm{cm}^{2}$; e o outro grupo foi usado como controle. Utilizamos o método pontual, com a caneta do aparelho em contato direto com a pele do animal. Os dois grupos foram divididos em subgrupos, e os animais destes, sacrificados em períodos distintos, sendo no $8^{\circ}$ e $15^{\circ}$ pós-operatório. O tendão foi excisado e submetido a análise histológica pela microscopia de luz, onde foi observado a presença de células inflamatórias, fibroblastos, vascularização e deposição de colágeno. Houve diferença estatisticamente significante $(\mathrm{p}<0.05)$, entre controle e tratamento na deposição de colágeno e presença de células inflamatórias. Este estudo, sugestiona que a terapia a laser, proporciona a aceleração da cicatrização na tenotomia calcâneana em ratos, pelo aumento da deposição de colágeno, tanto na fase inicial como na tardia do tratamento.

Palavras-chave: laser; tenotomia; cicatrização. 


\begin{abstract}
TAVARES, M. R. (2002). Effect of therapeutic laser in tendon healing: study experimental in rats. Ribeirão Preto, 2002. p. Dissertação (Mestrado) - Escola de Engenharia de São Carlos/ Faculdade de Medicina de Ribeirão Preto, Universidade de São Paulo.
\end{abstract}

Low-potency laser therapy has been used as a means of minimizing the hazardous effects of inflammation and accelerating healing in damaged tissues. This paper aims at observeving the alterations caused by diode AsGa (904nm), laser in the calcaneal tendon of rats. Thirty $235 \mathrm{~g}$ (average weight) Wistar rats were divided into 2 groups - one with 20 and other with 10 animals, all of which underwent right calcaneal tendon tenotomy. One group started laser treatment at a dosege of $4 \mathrm{~J} / \mathrm{cm}^{2}$ 24hours after surgery, the other being used as control. The punctual method was employed and the appliance pen kept in direct contact with animal's skin. Both groups were divided into subgroups, the animals of which were sacrificed in different times - on the $8^{\text {th }}$ and $15^{\text {th }}$ postoperative day, respectively. The tendon was excised and submitted to histology analysis using light microscopy, which revealed the presence of inflammatory cells, fibroblasts, vascularization and collagen deposition. There was a statistically significant difference $(\mathrm{p}<0.05)$ between the control and the treatment as far as collagen deposition at the presence of inflammatory cells are concerned. This study suggests that laser therapy accelerates healing in calcanean tenotomy in rats by increase collagen deposition both in the early and late parts of the treatment.

Key-words: laser; tenotomy; healing. 


\section{INTRODUÇÃO}

\subsection{TENDÃO}

DÂNGELO \& FATTINI (2001) explica que um músculo esquelético, possui uma porção média e extremidades. A porção média é carnosa, vermelha no vivente e recebe o nome de ventre muscular. As extremidades, quando cilindróides ou em forma de fita, são chamadas tendões e quando laminares, são denominadas de aponeuroses. Ambos tendões e aponeuroses, são esbranquiçados e brilhantes, muito resistentes e inextensíveis.

O tendão é definido por HOLLENSEHEAD (1980) como um tecido que liga um músculo a outras estruturas; assim, uma das extremidades está sempre ligada a um músculo. $\mathrm{Na}$ outra extremidade, as fibras do tendão sempre se aderem com o tecido fibroso da estrutura a que se unem - comumente ao osso, onde elas são contínuas ao mesmo tempo, com uma cobertura fibrosa externa, o periósteo.

CARLSTEDT (1987) e JUNQUEIRA \& CARNEIRO (1995) afirmam que os tendões são compostos por fibras colágenas, paralelas entre si. Entretanto, trata-se de um tipo de tecido conjuntivo, o denso. Essas fibras foram formadas em resposta a trações exercidas, em um determinado sentido, orientadas de modo a oferecer, o máximo de resistência às forças que normalmente atuam sobre o tecido.

Entretanto, CURRIER \& NELSON (1992) relataram que o tendão, é constituído por fibroblastos e uma matriz extracelular, na qual estão imersas proteínas fibrosas de 
colágeno e elastina, proteoglicanas, glicoproteínas e mucopolissacarídeos. O colágeno é o maior componente da matriz extracelular, compreendendo $86 \%$ a $95 \%$ do peso úmido do tendão.

As superfícies dos tendões são esbranquiçadas e brilhantes devido ao epitendão, que é ligado á membrana sinovial. Internamente a este, as fibras tendinosas são agrupadas em um fina membrana de tecido conectivo, o endotendão, que contém vasos sangüíneos e linfáticos. Cada fibra tendinosa é constituída de estruturas mais finas, as fibrilas (CARLSTEDT, 1987). Estas se dividem em sub-fibrilas, que por sua vez, se dividem em micro-fibrilas, que são formadas por tropocolágeno (KASTELIC et al., 1978).

A orientação macromolecular das fibras de colágeno tendinoso não é estável. Em diversos estudos, foram observadas alterações na orientação e uma conseqüente reorganização ( em uma lesão), dos componentes colágenos da matriz extracelular, em função da idade, dos exercícios físicos, da desnervação e reparação do tendão (MELLO et al., 1975; VILARTA \& VIDAL, 1989; VIDAL \& CARVALHO, 1990).

CARLSTEDT (1987) relata que existem muitos fatores que afetam as propriedades físicas do colágeno, dentre eles: a maturação, o envelhecimento, o treinamento, a imobilização, o tratamento com glucocorticoides, as injeções de corticosteróides a nível local, a diabetes, a gravidez e o período pós-parto, o latirismo, a deficiência de vitamina $\mathrm{C}$ e os anti-inflamatórios não hormonais.

\subsection{CICATRIZAÇÃO TENDINOSA}

Logo que ocorre a lesão, inicia-se uma resposta vascular. Primeiramente, com uma vasoconstricção (por ação da noradrenalina e contração do endotélio) e minutos depois, com uma vasodilatação. Conseqüentemente, células inflamatórias são atraídas para o local, tais como: neutrófilos, leucócitos, plaquetas e eritrócitos, sendo esses dois últimos, responsáveis pela diminuição do extravasamento de sangue no local. Com a ação da histamina alterando a permeabilidade vascular, ocorre a formação do edema local. Este estágio está dentro da 
inflamação aguda, que perdura por cerca de 1 à 3 dias e caminha para a cura, com o tecido de granulação, ou uma inflamação crônica (BAXTER, 1994).

Vinte e quatro horas após a agressão, os fibroblastos e as células endoteliais vasculares, começam a proliferar para formar (em três a cinco dias) o tecido de granulação, característico da cicatrização. Tem-se então, quatro componentes: formação de novos vasos sangüíneos (angiogênese), migração e proliferação dos fibroblastos, deposição da matriz extracelular e maturação e organização do tecido fibroso (remodelamento).

Para que ocorra a angiogênese, são necessárias quatro etapas: (1) degradação proteolítica da membrana basal do vaso-mãe; (2) migração de células endoteliais, na direção do estímulo angiogênico; (3) proliferação das células endoteliais, na região imediatamente posterior à frente inicial de células em migração; e (4) maturação das células endoteliais e organização destas em tubos capilares. Estes novos vasos permitem a passagem de proteínas e hemácias para o espaço extracelular, portanto o tecido de granulação recente estará freqüentemente edemaciado.

A migração e proliferação dos fibroblastos são desencadeados por fatores de crescimento e citocinas fibrogênicas, parcialmente derivadas dos macrófagos inflamatórios (COTRAN et al., 2000).

Durante a formação do tecido de granulação, os fibroblastos adquirem características estruturais, funcionais, imunológicas e químicas diferentes dos tecidos fibroblásticos normais e portanto são chamados miofibroblastos (BAXTER, 1994).

De acordo com CURRIER \& NELSON (1992) os miofibroblastos aparecem 5 dias após a lesão, diminuem sua população de 21 à 60 dias e reaparecem na fase de maturação de 60 à 360 dias.

GIGANTE et al. (1996) demonstrou as fases da cicatrização no tendão calcâneo em ratos, e relata que com o término da inflação aguda em torno de sete dias após a lesão, iniciase a fase de proliferação, de 7 á 15 - 20 dias. Esta fase é marcada pela angiogênese, e subseqüente proliferação fibroblástica, uma desorganização da matriz, o aparecimento de 
fibras colágeno com um diâmetro maior ( $400-600 \mathrm{~A}^{\circ}$ ) do que na fase prévia, presença de fibras elásticas imaturas, em máxima concentração ( 30\%) e fibras colágenas ao longo do eixo axial longitudinal do tendão com três semanas após a lesão.

A fase de remodelação ( 21 dias após a lesão ) é marcada por uma série de eventos, dentre eles estão: um aumento e organização da matriz; diminuição do número de células; retorno da vascularização e inervação normal; fibras de colágeno com um diâmetro de 800$1000 \mathrm{~A}^{\text {o}}$; fibras elásticas exibem um aumento da deposição de elastina. Com seis a oito semanas o tendão assume um aspecto normal, porém ainda com fibras colágenas relativamente imaturas.

O tendão é de lenta cicatrização e necessita de até oito semanas de imobilização, para a produção e remodelação do colágeno.

A imobilização freqüentemente resulta em: atrofia muscular, atrofia e lesão da cartilagem articular, osteoartrite, necrose da pele, infecção, aderências tenocutâneas, rerupturas e tromboflebites (ENWEMEKA, 1989; ENWEMEKA, 1992).

Vários estudos foram realizados, no sentido de minimizar os problemas da cicatrização tendinosa. Os que mais se destacam estão relacionados com: a técnica cirúrgica empregada (STRICKLAND, 1989), mobilizações e imobilizações (ENWEMEKA, 1992), utilização de recursos físicos para acelerar o processo de reparação tecidual ( ALBERGEL et al, 1984; GUN et al, 1997; REDDY et al, 1998a; SHIMITT et al, 1993).

A radiação a laser tem sido usada para acelerar os processos cicatriciais, tanto em estudos experimentais, quanto na prática fisioterapêutica (SILVA et al, 1998; VEÇOSO, 1993). 


\subsection{O LASER TERAPÊUTICO}

\subsubsection{Definição}

LEHMANN \& LATEUR (1994) relataram que o laser é uma onda eletromagnética, constituída por um feixe de fótons de mesma freqüência em coluna, com o comprimento de onda em fase.

VEÇOSO (1993) esclarece que a palavra LASER, constitui-se numa sigla: Light Amplification by Stimulated Emission of Radiation, que quer dizer, Amplificação da Luz por Emissão Estimulada de Radiação.

\subsubsection{Histórico}

O laser foi idealizado por Albert Einstein em 1917, onde expôs os princípios físicos da emissão estimulada (o fenômeno laser) (VEÇOSO, 1993).

Somente 33 anos depois, em 1950, Townes, Gordom e Zeyger contruiram um oscilador que operava na banda de ondas milimétricas, chamado MASER (Microave Amplification by Stimulated Emission of Radiation) (BAXTER, 1994).

Em 1958, Schawlow e Townes propuseram o desenvolvimento do "maser óptico", porém o primeiro a desenvolvê-lo foi Theodore H. Maiman em 1960, com o emissor de laser a rubi.

A partir de 1960, houve um grande avanço nos equipamentos de laser. Primeiramente, possibilitando cirurgias oftálmicas com sucesso (1961), mais tarde com o desenvolvimento do laser semicondutor, em 1962 (VEÇOSO, 1993).

COLLS (1984) afirma que a adaptação do laser terapêutico ocorreu após 1965.

Desde a sua concepção, os lasers encontraram uma aplicação imediata na medicina, e particularmente na cirurgia, porém em estudos mais recentes, os pesquisadores voltaram-se para as possíveis aplicações clínicas das interações atérmicas da luz do laser com os tecidos (BAXTER, 1998). 


\subsubsection{Classificação}

Segundo VEÇOSO (1993) o laser é classificado em "alta potência" (com potencial destrutivo) e em "baixa potência"(sem potencial destrutivo).

Porém, COLLS (1984) classifica-o em três níveis de potência, empregados pelo emissor: a. power-laser (com alta potência e potencial destrutivo, utilizado em cirurgias, exemplos: $\mathrm{CO}_{2}$ e argônio); b. mid-laser (potências médias e sem potencial destrutivo, exemplo: arsenieto de gálio) e c. soft-laser (potências baixas e sem potencial destrutivo, exemplo: hélio-neônio).

\subsubsection{Princípios Físicos da Radiação Laser}

Segundo COLLS (1988) a onda é uma perturbação ou distúrbio transmitido através do vácuo ou de um meio gasoso, líquido ou sólido.

As ondas variam de acordo com alguns parâmetros:

- Ciclo: é a menor porção não repetitiva da onda.

- Período: é o tempo gasto para efetuar um ciclo. Representado por "T" e medido em segundos (s).

- Comprimento de onda: é a distância percorrida pela onda em um período. Representado por lâmbida e medido em metros (m).

- Frequência: é o número de ciclos realizados em um segundo. Representado por "f" e sua unidade é dada em hertz $(\mathrm{Hz})$, portanto $1 \mathrm{~Hz}=1$ ciclo/segundo.

Se um período é o tempo gasto para realizar um ciclo e a frequência o número de ciclos por segundo, matematicamente tem-se: $\mathrm{T}=1 / \mathrm{f}$ e $\mathrm{f}=1 / \mathrm{T}$ (VEÇOSO, 1993). COLLS ( 1988) cita além destes acima, outro parâmetro:

- Velocidade de Propagação: toda onda eletromagnética se propaga com uma velocidade fixa no vácuo, que é de 300.000 kilômetros por segundo $(\mathrm{Km} / \mathrm{s})$. É representada por (c). 
O mesmo autor explica alguns termos utilizados, são eles:

- Energia: é a capacidade de efetuar um trabalho, sendo representado por "E".

- Potência: é a quantidade de energia utilizada em um intervalo de tempo (t), simbolizada por "P" e sua unidade é o watts (W). Portanto, a relação entre potência e energia é: $\mathrm{P}=\mathrm{E} / \mathrm{t}$ ou $\mathrm{E}=\mathrm{P} \times \mathrm{t}$.

- Densidade de Energia(D): é a quantidade de energia utilizada em uma determinada superfície (S), onde tem-se: $\mathrm{D}=\mathrm{E} / \mathrm{S}$, e "E" é dado em joules e "S" em $\mathrm{cm}^{2}$.

HALLIDAY \& RESNICK (1981) relatam que através da teoria proposta por Max Planck em 1900, o transporte de energia pelas ondas eletromagnéticas é feito por meio de "pacotes", chamados de quantuns ou fótons, que percorrem o espaço realizando movimentos oscilatórios. O nível de energia dos fótons,o qual a unidade é dado em eletrovolt (ev) ou joule (J), determina as características de propagação das ondas eletromagnéticas. Com base nesta teoria tem-se a expressão: $E=h \times f$, onde "E" é a energia irradiada, "f" é a frequência e "h" é a constante de Planck (6,63 × 10 $0^{-34} \mathrm{~J}$ x segundo).

De acordo com BAXTER (1998) para que haja a produção de laser, é necessário o "bombeamento" com energia (sendo esta de fonte elétrica) de substâncias gasosas (tais como o hélio e neônio) ou semicondutores ( de arsenieto e gálio ou arsenieto, gálio e alumínio), emitindo assim um feixe de luz ( visível ou não dependendo do comprimento de onda).

\subsubsection{Laser Semicondutor}

O semicondutor é a substância que possui uma condutividade inferior a dos metais. Os mais usados são: o silício, o germânio e o arsenieto de gálio.

A partir da passagem da corrente elétrica através das substâncias selecionadas, serão produzidas sucessivas combinações de partículas, acompanhadas de desprendimento de energia luminosa. 
Entretanto, este processo depende da intensidade da corrente elétrica, que tem de ser suficiente, para a estimulação e recombinação de partículas necessárias, ocorrendo portanto, a produção de uma radiação ordenada (BAXTER, 1994).

\subsubsection{Características da Radiação Laser}

Segundo BAXTER (1998) o laser terapêutico possui algumas características que difere da radiação gerada por outras fontes ( por exemplo: lâmpadas infravermelhas) são elas:

- Monocromaticidade: que quer dizer "uma só cor"; a maior parte da radiação emitida pelo aparelho de uso terapêutico, agrupa-se em torno de um único comprimento de onda, com uma amplitude limitada. O comprimento de onda determina os efeitos terapêuticos específicos da laserterapia, portanto este parâmetro determina, quais as biomoléculas específicas que absorverão a radiação, ocasionando em uma interação fotobiológica subjacente, a qualquer efeito terapêutico específico.

- Colimação: os raios de luz ou fótons produzidos pelo laser, não promovem nenhuma ou quase nenhuma divergência da radiação emitida, ao longo da distância percorrida, mesmo através dos tecidos. É também chamada por COLLS (1988), de unidirecionalidade.

- Coerência: ocorre o sincronismo entre o tempo( coerência temporal) e o espaço (coerência espacial) dos fótons emitidos pelo laser.

Também de acordo com COLLS (1988) estas três características (monocramaticidade, unidirecionalidade e coerência) produzem uma quarta, que é o "alto brilho", sendo esta a propriedade básica da utilização do laser, como instrumento terapêutico e cirúrgico. Esclarece ainda que a grande quantidade de energia produzida é focalizada em uma superfície reduzida, permitindo obter das emissões a laser, uma elevada densidade de potência e intensidade. 


\subsubsection{O Laser de Arsenieto de Gálio ( AsGa)}

Segundo BAXTER (1994) é uma radiação obtida através da estimulação de um diodo semicondutor, formado por cristais de arsenieto de gálio, que é também conhecido como laser semicondutor ou laser diodo.

Os autores GONZÁLEZ \& CRUAÑAS (1988) afirmam que ao adicionar telúrio a um dos cristais de arsenieto de gálio, está conferindo-lhe uma característica elétrica positiva (onde faltam elétrons). No segundo cristal, acrescentando-se zinco, resultará na característica elétrica negativa (com excesso de elétrons). Com esta união tem-se um diodo semicondutor.

A passagem da corrente elétrica nesse diodo, resultará na obtenção de energia, que amplificadas pelas extremidades do diodo, escapam e formam a radiação a laser.

Ainda de acordo com esses autores, tem-se as características básicas do laser AsGa, que são:

- Regime de Emissão Pulsado;

- Comprimento de Onda 904 nanômetros (nm);

- Cor Infravermelha (invisível a “olho nu”).

VEÇOSO (1993) assegura que este tipo de laser, apresenta um potencial terapêutico em lesões profundas dos tipos: articular, muscular, ligamentar, entre outras.

COLLS (1984) relatou que o laser AsGa tem a potência superior a do $\mathrm{He}-\mathrm{Ne}$, entretanto, possui um maior poder de penetração.

KOLARI (1985) confirmou que além de possuir um maior poder de penetração, em torno de 1,4 milímetros (mm), também afirmou algumas outras vantagens do laser As-Ga, o seu tamanho é reduzido, o custo do aparelho é menor (em relação aos outros presentes no mercado), ele é seguro e de simples aplicação. 


\subsubsection{A Interação Laser-Tecido}

$\mathrm{Na}$ laserterapia de baixa intensidade, ocorre reações não térmicas (atérmicas) da luz no tecido. Esta luz pode interagir com o tecido de duas formas:

- Espalhamento da luz incidente: mudança na direção de propagação da luz, enquanto esta transita nos tecidos, devendo-se à variabilidade nos índices refrativos dos componentes do tecido, com relação à água. Este espalhamento irá provocar um certo "alargamento" do feixe, durante sua passagem no tecido irradiado, ocorrendo uma rápida perda da coerência.

- Absorção da luz por um cromóforo: uma biomolécula através de sua configuração eletrônica ou atômica, pode ser excitada por um fóton ou fótons incidentes (BAXTER, 1998).

Dentre as duas, a segunda é considera a mais importante e é melhor explicada por GONZÁLEZ \& CRUAÑAS (1988). Segundo eles, esta é chamada de “absorção seletiva”. Os tecidos dos organismos animais, tem uma função "fotorreguladora", a partir de certos "fotorreceptores", capazes de absorver um fóton de um determinado comprimento de onda, levando a provocar uma transformação da atividade funcional e metabólica da célula.

\subsubsection{Efeitos Fisiológicos do Laser de Baixa Intensidade}

COLLS (1984) explica os efeitos do laser, que são divididos em: efeitos primários, secundários e terapêuticos.

\subsubsection{Efeitos Primários ou Diretos}

Esses efeitos diretos, subdividem-se em três outros efeitos: bioquímicos, bioelétricos e bioenergéticos.

\subsection{Bioquímico}

Este por sua vez, se divide em dois efeitos básicos: 
- Liberação de substâncias pré-formadas: tais como histamina, serotonina e bradicinina.

- Modificações das reações enzimáticas: proporciona modificações estimulatórias ou inibitórias em reações enzimáticas normais, tais como: produção de ATP (adenosina trifosfato), inibição da síntese de prostaglandina e lise de fibrina.

\subsection{Bioelétrico}

Através da produção de ATP (ação indireta) e mobilidade iônica ( ação direta através dos fótons), ocorre a potencialização da bomba de sódio e potássio.

\subsection{Bioenergético}

O aporte energético da radiação a laser, tem a capacidade de normalizar (sem trofismos e sem fisiologismos) o contingente energético, que coexiste com o contingente físico de cada indivíduo.

\subsubsection{Efeitos Secundários ou Indiretos}

Segundo VEÇOSO (1993) existem os seguintes efeitos:

- Estímulo á microcirculação: com a liberação da histamina pelo laser, ocorre a paralisação dos esfíncteres pré-capilares, como conseqüência, o fluxo sanguíneo se vê aumentado.

- Estímulo ao trofismo celular: com o aumento na produção de ATP, a velocidade mitótica é também aumentada, o que proporciona em escala tissular, aumento da velocidade de cicatrização e também melhor trofismo dos tecidos.

\subsubsection{Efeitos Terapêuticos}

COLLS (1984) descreve os efeitos terapêuticos da seguinte maneira:

- Efeito Analgésico;

- Efeito Antiinflamatório;

- Efeito Antiedematoso;

- Efeito Cicatrizante. 


\subsection{Efeito Analgésico}

Explica-se por vários fatores:

- Fator antiinflamatório: a nível local reduzindo a inflamação, provocando a reabsorção de exsudatos e favorecendo a eliminação de substancias alógenas, através do estímulo a microcirculação.

- Interferência da mensagem elétrica: através da manutenção ao potencial de membrana e como a mensagem elétrica constitui-se em uma despolarização, este processo de inversão de polaridades seria dificultado, com isso proporcionaria uma menor sensação dolorosa.

- Estimulando, direta ou indiretamente, a liberação de beta endorfinas.

- Evitando a redução do limiar de excitabilidade dos receptores dolorosos: através da redução na síntese de prostaglandinas, decresce a potencialização da bradicinina e como consequiência, tem-se a manutenção do limiar de excitabilidade dos receptores dolorosos.

- Provocando a normalização e o equilíbrio da energia no local da lesão: com a liberação de histamina e bradicinina, ocorre a sensibilização dos receptores dolorosos, que é corrigido através do aumento da permeabilidade de vênulas e das dilatações das arteríolas.

\subsection{Efeito Antiinflamatório}

Ainda de acordo com COLLS (1984) este efeito justifica-se por dois fatores:

- Interferência na síntese de prostaglandinas: sua redução decresce as alterações proporcionadas pela inflamação.

- Estímulo á microcirculação: garantindo um aporte eficiente de elementos nutricionais e defensivos para região lesada, favorecendo sua resolução.

\subsection{Efeito Antiedematoso}

Também justifica-se por dois fatores:

- Estímulo a microcirculação: favorece melhores condições de drenagem do plasma que forma o edema. 
- Ação fibrinolítica: proporciona a resolução efetiva do isolamento causado pela coagulação do plasma, que determina o edema duro.

\subsection{Efeito Cicatrizante}

Para a maioria dos autores ( COLLS, 1984; HERRERO, 1988; SILVA et al, 1998; VEÇOSO,1993) este é o efeito que mais se destaca. É caracterizado por:

- Incremento á produção de ATP: o laser eleva a produção de ATP (KARU et al, 1995) proporcionando um aumento da atividade mitótica (COLLS, 1984; HERRERO, 1988; SILVA et al, 1998; VEÇOSO,1993) e aumento da síntese de proteína, por intermédio da mitocôndria (GRECO et al, 1989; PASSARELLA et al, 1988) tem-se como conseqüência, o aumento da regeneração tecidual em um processo de reparação ( COLLS, 1984; HERRERO, 1988; SILVA et al, 1998; VEÇOSO,1993).

- Estímulo à microcirculação: aumenta o aporte de elementos nutricionais associado ao aumento da velocidade mitótica, facilitando a multiplicação das células (COLLS, 1984; SILVA et al, 1998).

- Formação de novos vasos a partir dos pré-existentes (BIBIKOVA et al, 1994;

COLLS, 1984; GONZÁLEZ \& CRUAÑAS, 1988; SILVA et al, 1998; VEÇOSO,1993). LONGO et al (1987), ANNEROTH et al (1988) e TATARUNAS et al (1998) indicavam a utilização do laser As-Ga para obter cicatrização dos tecidos.

REDDY et al (1998a) demonstraram experimentalmente, que o laser terapêutico possui um efeito cicatrizante através da estimulação da matriz colagenosa. Ele utilizou 24 coelhos da raça Nova Zelândia, onde realizou uma tenotomia no tendão de Aquiles, seguido de sutura. Os animais foram imobilizados e submetidos a uma dose de $1 \mathrm{~J} /$ dia do laser He-Ne $(632,8 \mathrm{~nm})$ por 14 dias no tendão de Aquiles. No $15^{\circ}$ dia os coelhos eram sacrificados e o tendão excisado para posterior análise bioquímica. Observaram um aumento de $26 \%$ de colágeno quando comparando com o grupo controle. 
ABERGEL et al (1984) em seus experimentos, também demonstraram que o uso do laser estimulou a produção de colágeno no processo de cicatrização tecidual.

\subsubsection{Dosimetria}

Os autores NEMTSEV \& LAPSNIN (1997) descrevem alguns termos mais usados como parâmetros para a dosimetria:

- Tipo de emissão: dois tipos, contínua ( exemplo: He-Ne) e pulsada (exemplo: AsGa).

- Potência exata de emissão: de acordo com o tipo de emissão e a potência do aparelho, tem-se a energia real. Quanto maior o aporte de energia, maior a potência.

- Energia total do tratamento: será resultante do tempo total de exposição da potência emitida pelo aparelho.

- Energia total por ponto de aplicação: é o resultado da divisão do total da energia emitida, pelo número de pontos ou aplicação em uma determinada área.

- Densidade de energia: é a relação entre a energia liberada pelo laser e a superfície de exposição a este tratamento.

- Densidade de potência: é a relação existente entre a potência real e a superfície de exposição ao laser.

SILVA et al (1998) relata com relação ao tempo de aplicação, que quanto maior a potência, menor é o tempo necessário para aplicar uma certa quantidade de energia em uma área.

Para descobrir o tempo de aplicação é necessário ter conhecimento de:

- $\quad$ dose $\left(\mathrm{J} / \mathrm{cm}^{2}\right)$, que se deseja aplicar;

- $\quad$ potência de emissão utilizada;

- área a ser irradiada (HERRERO et al, 1988). 
COLLS (1984) descreveu um esquema orientativo, para critérios de dose:

Efeito analgésico 2 a $4 \mathrm{~J} / \mathrm{cm}^{2}$

Efeito antiinflamatório 1 a $3 \mathrm{~J} / \mathrm{cm}^{2}$

Efeito cicatrizante 3 a $6 \mathrm{~J} / \mathrm{cm}^{2}$

Efeito circulatório 1 a $3 \mathrm{~J} / \mathrm{cm}^{2}$

Descreve também com relação ao estágio do processo inflamatório:

Agudo Doses baixas (1 a $3 \mathrm{~J} / \mathrm{cm}^{2}$ )

Subagudo Doses médias (3 a $\left.4 \mathrm{~J} / \mathrm{cm}^{2}\right)$

Crônico Doses altas $\left(5\right.$ a $\left.7 \mathrm{~J} / \mathrm{cm}^{2}\right)$

É considerado ainda, o caráter inibitório, com doses acima de $8 \mathrm{~J} / \mathrm{cm}^{2}$, e o caráter estimulatório, doses abaixo de $8 \mathrm{~J} / \mathrm{cm}^{2}$.

Para evidenciar ainda mais a interação do laser terapêutico, com os tecidos, e levando-se em conta, uma utilização cada vez mais rotineira na prática experimental e fisioterapêutica, faz-se necessário este estudo.

\subsection{OBJETIVO DO TRABALHO}

Analisar o efeito do laser terapêutico As-Ga, na cicatrização do tendão calcâneo de ratos, através da microscopia de luz. 


\section{MATERIAL E MÉTODOS}

\subsection{APARELHO DE LASER}

O aparelho de laser utilizado, foi um modelo clínico portátil, o LASERPULSE, produzido pela IMBRAMED Ltda. (figura 1). A caneta usada (figura 2) foi de AsGa com comprimento de onda de $904 \mathrm{~nm}$, e com pico de potência de $15 \mathrm{~W}$, potência média de 3 a 7 $m W$, com a duração de pulso de $180 \mathrm{~ns}$ e frequência de $2000 \mathrm{~Hz}$.

Ao final do experimento, o aparelho foi aferido no laboratório de Ótica do Departamento de Física da Escola de Engenharia de São Carlos, ao qual foi encontrada uma potência média de $3,7 \mathrm{~mW}$.

\subsection{OS ANIMAIS}

Nesta pesquisa foram utilizados ratos albinos, machos da linhagem WISTAR, de idade adulta e peso variando de 200 a $250 \mathrm{~g}$, provenientes do Biotério Central da Universidade de Alfenas - UNIFENAS. Esses animais passaram, por um período de adaptação de sete dias, junto ao Biotério Experimental da UNIFENAS - Campus Campo Belo (MG).

Quarenta animais hígidos foram utilizados, entretanto 10 destes animais foram eliminados do experimento, por intercorrências durante a realização do estudo. Estas 
intercorrências foram seis mortes, dois comeram o local da incisão e dois apresentaram ulceração da pele com infecção.

Durante o experimento, os ratos permaneceram em gaiolas de polietileno, contendo quatro animais, com condições de temperatura, iluminação e ventilação adequadas, e também com livre acesso à água e alimentação.

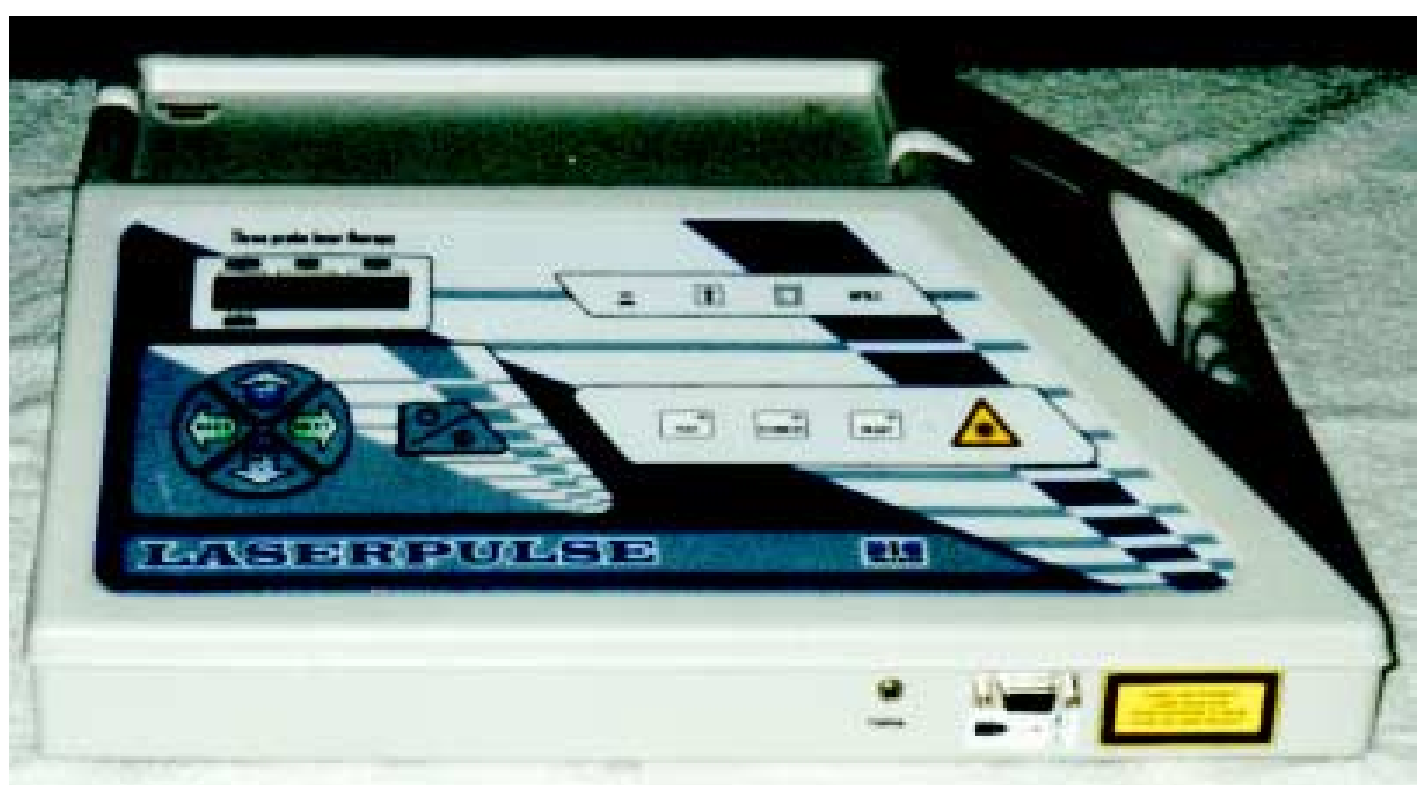

FIGURA 01 - Aparelho de laser utilizado para o tratamento.

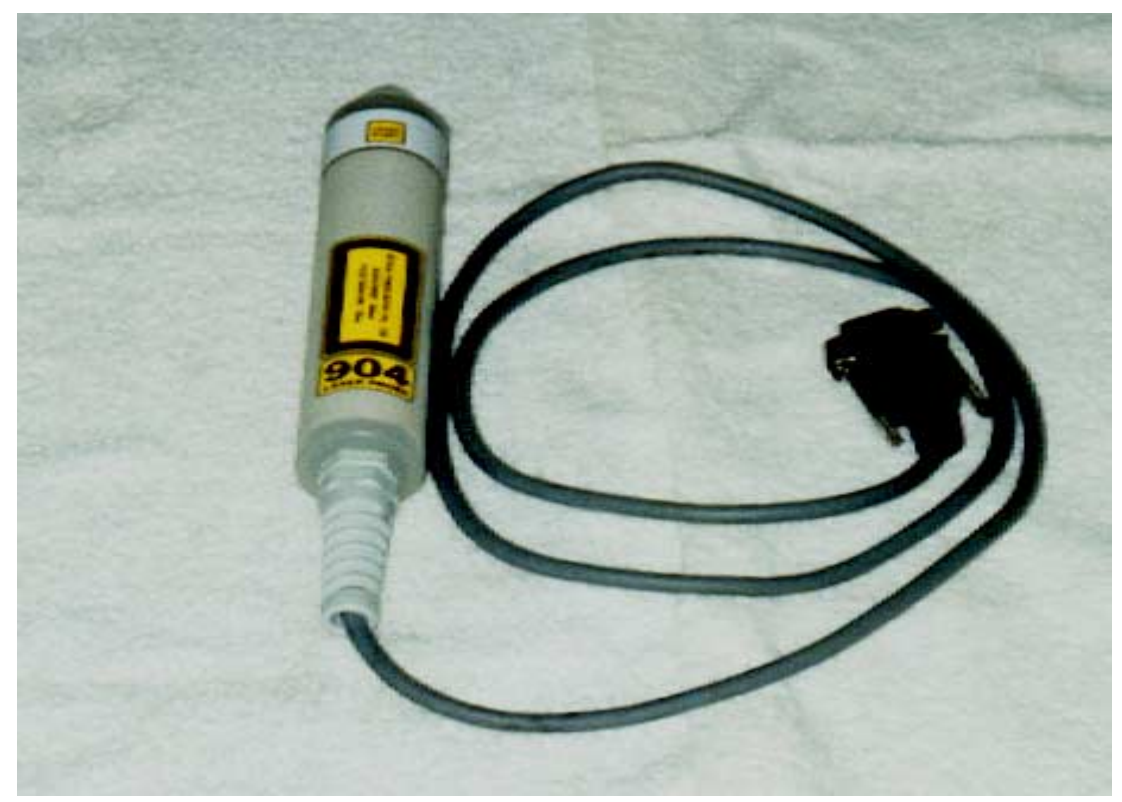

FIGURA 02 - Caneta do laser AsGa 904nm 


\subsection{PROCEDIMENTO EXPERIMENTAL}

O procedimento cirúrgico foi realizado no Laboratório de Biologia da Faculdade de Fisioterapia de Campo Belo, da Universidade de Alfenas.

A anestesia de todos os grupos, foi realizada por inalação de Éter Etílico, em uma Câmara de Dessecação.

Logo após, foi realizada a tricotomia na perna direita (região posterior) dos animais, e em seguida foram realizados os seguintes passos:

- Posicionamento do animal em decúbito ventral e fixação do membros;

- Anti-sepsia da pele com álcool iodado 4\%;

- Colocação de campos frenestrados;

- Incisão longitudinal na região posterior do tendão calcâneo direito;

- Isolamento (figura - 03) e tenotomia total do tendão calcâneo direito (figura 04) na região intermédia (entre a junção miotendinosa e a inserção);

- Fechamento da pele com sutura simples, com fio de poliéster / algodão 2-0;

- Aplicação de álcool iodado sobre a sutura, sendo esta deixada sem curativos.

\subsection{GRUPOS DE ANIMAIS}

Após a cirurgia, os animais foram identificados e divididos aleatoriamente em dois grupos, um com tratamento a laser (grupo A) e outro para controle (grupo B) os quais, possuindo respectivamente vinte e dez animais, subdivididos em dois subgrupos, com dez animais $\left(A_{1}\right.$ e $\left.A_{2}\right)$ e cinco animais $\left(B_{1}\right.$ e $\left.B_{2}\right)$.

O grupo A recebeu aplicações com o laser vinte e quatro horas após a cirurgia, com irradiações diárias por sete dias consecutivos.

Os animais foram sacrificados no $8^{\circ}$ e $15^{\circ}$ dia pós-operatório e distribuídos nos grupos conforme a tabela 1. 
FIGURA 03 - Dissecação do tendão calcâneo.

FIGURA 04 - Tenotomia do tendão calcâneo. 
Tabela 1 Grupos experimentais

\begin{tabular}{cccc}
\hline GRUPOS & N & AL & DS \\
\hline$A_{1}$ & 10 & 7 & $8^{\text {o }}$ \\
$A_{2}$ & 10 & 14 & $15^{\circ}$ \\
$B_{1}$ & 5 & - & $8^{\text {o }}$ \\
B $_{2}$ & 5 & - & $15^{\circ}$ \\
\hline
\end{tabular}

$\mathrm{N}=$ número de ratos por grupo

$\mathrm{AL}=$ Aplicações do laser

DS $=$ Dia do sacrifício do animal

\subsection{O TRATAMENTO COM LASER}

Baseando-se na orientação de COLLS (1984) e na dose utilizada por SCHIMITT et al (1993), os animais do grupo A, foram tratados com a dose de $4 \mathrm{~J} / \mathrm{cm}^{2}$. O método usado foi o da aplicação direta pontual (de apenas um ponto no local da tenotomia) sobre a pele do animal. As radiações foram feitas na mesma hora do dia, observando o período de vinte quatro horas entre as aplicações.

Os ratos foram posicionados e mantidos manualmente na posição, com auxílio de outra pessoa, que fixou o tronco e a cintura pélvica de tal maneira, que impossibilitou movimentos que interrompessem a aplicação.

Os animais do grupo B foram manuseados, somente para verificar se havia alterações cutâneas na ferida cirúrgica ou na região desta.

\subsection{SACRIFÍCIO DOS ANIMAIS}

Cada animal foi sacrificado com dose excessiva do anestésico (éter etílico) por via inalatória, seguido da dissecação do tendão calcâneo, onde procurou-se preservar ao máximo este. Foi feito um corte rente ao osso calcâneo e outro na junção miotendinosa do músculo tríceps sural, no membro pélvico direito. 


\subsection{PREPARAÇÃO DAS LÂMINAS E ANÁLISE HISTOLÓGICA}

Após a retirada do material, este foi colocado em um cassete e mantido em álcool $70 \%$ para a fixação, com volume 10 vezes superior ao volume da peça. Todo o material foi transportado até o Serviço de Patologia do Hospital das Clínicas da Faculdade de Medicina de Ribeirão Preto -USP, onde sofreu preparação das lâminas.

As lâminas dos tendões, foram preparadas da seguinte forma: (a) descrição, (b) desidratação, (c) difusão com xilol, (d) impregnação com parafina, (e) inclusão e (f) microtomia.

Foram realizados cortes longitudinais do local da lesão, sendo estes cortes de cinco micras, corados por Hematoxilina de Harris/ Eosina-Floxina e Tricrômico de Masson. (figuras 05 e 06).

As lâminas foram então analisadas por microscopia de luz, sendo que os resultados registrados por uma análise semiquantitativa da reação inflamatória, definida por: presença de células inflamatórias (macrófagos e leucócitos), fibroblastos, deposição de colágeno, neovascularização, presença de necrose e presença de microcalcificações, em graus que variam de: ausente (-), presença leve (+), presença moderada $(++)$ e presença acentuada $(+++)$. A presença de células inflamatórias, foi classificada também em focal $(F)$ e difusa (D), bem como a formação de novos vasos, nunca era ausente e sim normal (N).

\subsection{ANÁLISE ESTATÍSTICA}

$\mathrm{Na}$ análise estatística da histologia, foi usado os registros em cruzes (+), estes foram revertidos em valores numéricos, da seguinte maneira: 0 para (-), 1 para (+), 2 para (++) e 3 para $(+++)$; foram também considerados valores intermediários, tais como: 0,5 para $(-/+), 1,5$ para $(+/++)$ e 2,5 para $(++/+++)$. 
A análise estatística foi feita através do teste de contraste de médias, onde a média de cruzes de cada variável eram comparadas entre os grupos tratamento e nos diferentes tempos de sacrifício (JEKEL et al, 1999; TRIOLA, 2000).

$\mathrm{O}$ teste $t$ student foi realizado ao nível de significância $\mathrm{p}<0.05$, sendo que os dados serão classificados da seguinte maneira:

- para o nível de significância entre 0.05 e 0.01 , os valores são considerados significantes;

- para o nível de significância 0.01 até 0.001 , os valores são considerados muito significantes;

- para o nível de significância < 0.001 , os valores são considerados altamente significantes. 


\section{RESULTADOS}

\subsection{TESTE DE CONTRASTE DE MÉDIAS ENTRE OS GRUPOS TRATAMENTO E CONTROLE NOS DIFERENTES TEMPOS}

Os resultados deste teste, foram obtidos através da comparação de média de cruzes de cada variável, entre os grupos tratamento e controle nos diferentes tempos de sacrifício (JEKEL et al, 1999; TRIOLA, 2000). (valores individuais de cada animal nos anexos A, $\mathrm{B}, \mathrm{C}$ e D).

3.1.1 Grupo $\boldsymbol{A}_{1} \boldsymbol{x} \boldsymbol{B}_{1}($ tabela 02, figuras 05 e 06 )

\subsubsection{Presença de Células Inflamatórias}

Houve diferença estatística muito significante entre os grupos $(0.005<\mathrm{p}<0.0075)$. Observou-se também, uma maior presença de células inflamatórias, em valores absolutos no grupo $B_{1}$. 


\subsubsection{Vascularização}

Não houve diferença estatisticamente significante entre os grupos $(0.15<\mathrm{p}<0.2)$.

Em valores absolutos, os grupos têm graus de vascularização iguais.

\subsubsection{Presença de Fibroblasto}

Não houve diferença estatisticamente significante entre os grupos $(0.3<\mathrm{p}<0.4)$.

Em valores absolutos, observa-se maior presença de fibroblasto no grupo $\mathrm{B}_{1}$.

\subsubsection{Presença de Colágeno}

Houve diferença estatisticamente significante entre os grupos $(0.015<\mathrm{p}<0.02)$.

Observou-se também, uma maior presença de colágeno, em valores absolutos no grupo $\mathrm{A}_{1}$.

Tabela 02 - Resultados das médias nos grupos sacrificados no $8^{\circ}$ PO.

\begin{tabular}{|l|l|l|l|l|l|}
\hline \multicolumn{7}{|l|}{ Médias entre os grupos tratamento e controle $8^{\circ}$ PO } \\
\hline$A_{I} x B_{1}$ & \multicolumn{2}{|l|}{ Laser $n=10$} & \multicolumn{4}{l|}{ Controle $n=5$} & $p<0,05$ \\
\hline 08 dias & Média & $S$ & Média & $S$ & \multicolumn{1}{l|}{$t_{c}$} \\
\hline Células inflamatórias & 0,45 & 0,5 & 1,2 & 0,45 & 2,84 \\
Vascularização & 1 & 0,82 & 1 & 1,22 & 0 \\
Fibroblasto & 2,25 & 0,35 & 2,3 & 0,45 & 0,34 \\
Colágeno & 2,35 & 0,82 & 1,4 & 0.55 & 2,33 \\
\hline
\end{tabular}

$n=$ número de animais

$S=$ desvio padrão

$t_{c}=$ teste t calculado 


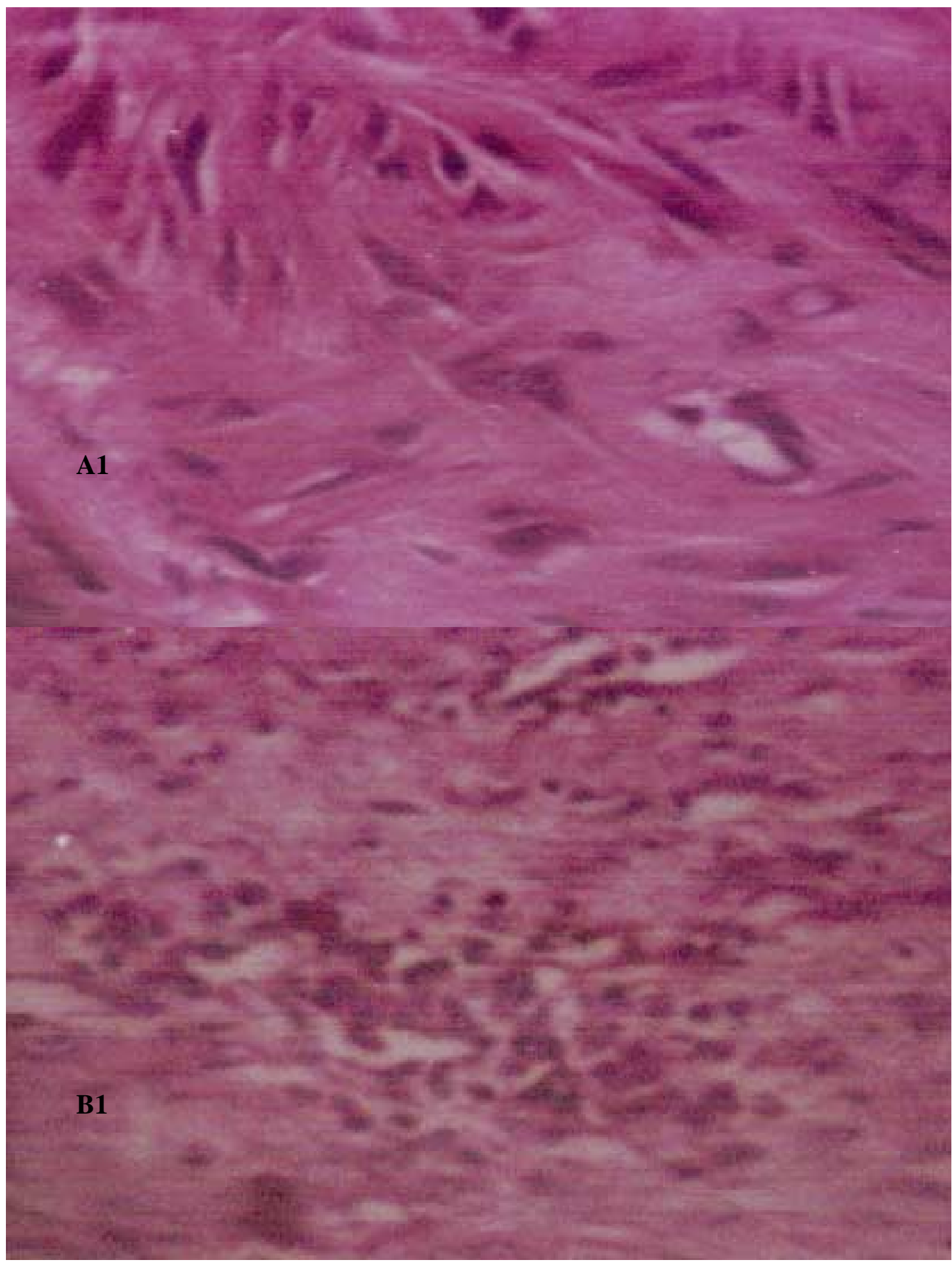

FIGURA - 05 Microscopia do tendão calcâneo de rato sacrificado no $8^{\circ} \mathrm{PO}$, corados pela Hematoxilina-Eosina. Corte longitudinal, mostrando maior presença de colágeno no grupo tratado e menor presença de células inflamatórias também no grupo tratado. Aumento de 400x (A1= grupo tratamento e B1= grupo controle). 


\section{MÉDIAS ENTRE OS GRUPOS A1 X B1}

\section{$\square$ Laser $\square$ Controle}

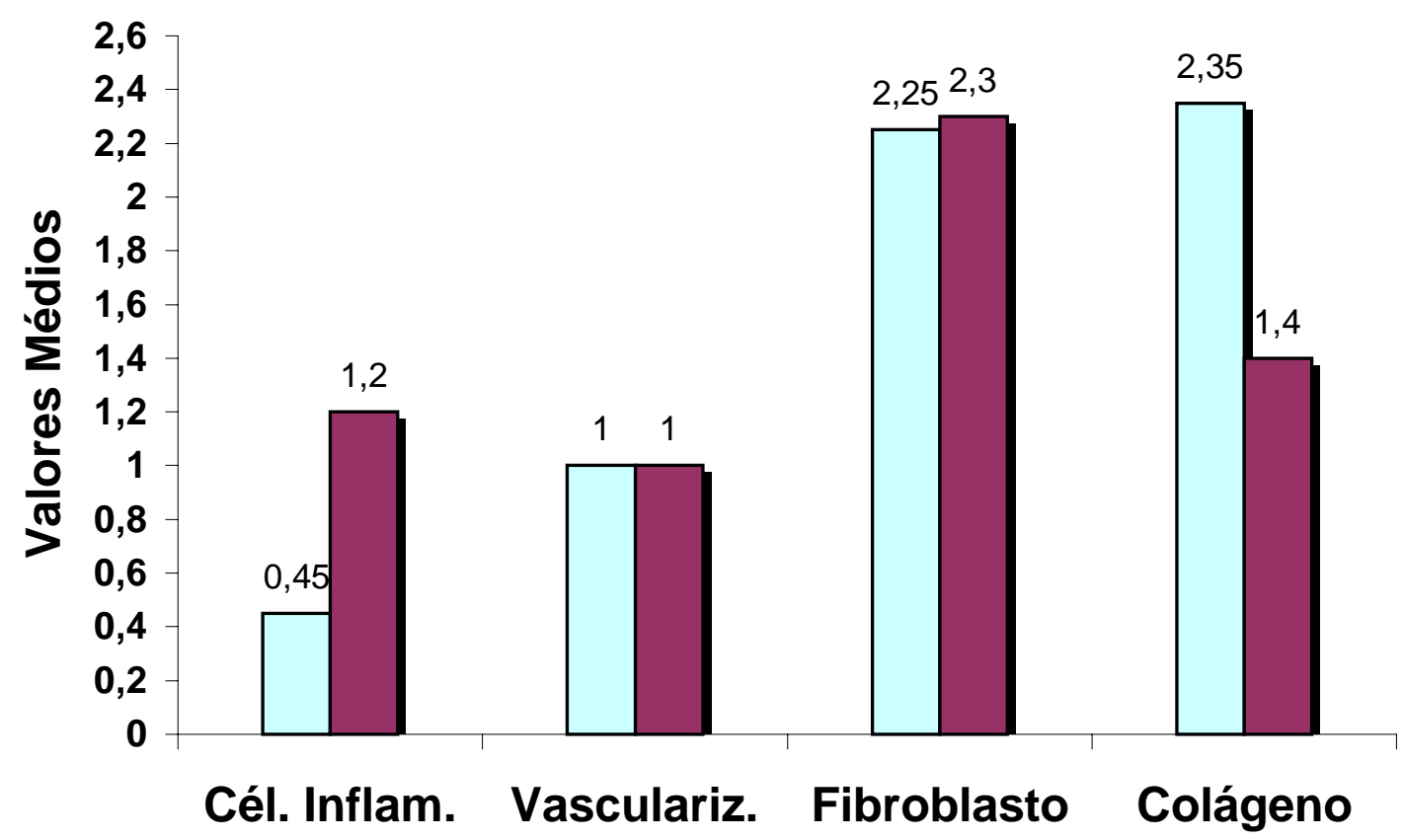

Figura 06 - Comparação das médias entre os grupos A1 e B1 - Histograma ilustrando o comportamento das variáveis no $8^{\circ} \mathrm{PO}$. Os resultados são obtidos através das médias de cada variável.

\subsubsection{Grupo $\boldsymbol{A}_{2} \boldsymbol{x} \boldsymbol{B}_{2}$ (tabela 03, figuras 07 e 08)}

\subsubsection{Presença de Células Inflamatórias}

Não houve diferença estatisticamente significante entre os grupos $(0.2<p<0.3)$. Observou-se também, um índice maior de presença de células inflamatórias, em valores absolutos no grupo $\mathrm{A}_{2}$. 


\subsubsection{Vascularização}

Não houve diferença estatisticamente significante entre os grupos $(\mathrm{p}>0.4)$. Em valores absolutos, o grupo $A_{2}$ tem grau de vascularização maior.

\subsubsection{Presença de Fibroblasto}

Não houve diferença estatisticamente significante entre os grupos $(0.05<\mathrm{p}<0.1)$. Em valores absolutos, observa-se maior presença de fibroblasto no grupo $\mathrm{B}_{2}$.

\subsubsection{Presença de Colágeno}

Houve diferença estatística altamente significante entre os grupos $(0.0005<\mathrm{p}<$ 0.0025). Observou-se também, um índice maior de presença de colágeno, em valores absolutos no grupo $\mathrm{A}_{2}$.

Tabela 03 - Resultados das médias nos grupos sacrificados no $15^{\circ} \mathrm{PO}$.

\begin{tabular}{|l|l|l|l|l|l|}
\hline \multicolumn{7}{|l|}{ Médias entre os grupos tratamento e controle $15^{\circ}$ PO } \\
\hline$A_{2} x B_{2}$ & \multicolumn{4}{l|}{ Laser $n=10$} & \multicolumn{4}{l|}{ Controle $n=5$} & $p<0,05$ \\
\hline 15 dias & Média & $S$ & Média & $S$ & $t_{c}$ \\
& & & & & \\
\hline Células inflamatórias & 1,1 & 0,74 & 0,8 & 0,45 & 0,83 \\
Vascularização & 1,7 & 0,82 & 1,6 & 0,55 & 0,24 \\
Fibroblasto & 1,7 & 0,48 & 2 & 0 & 1,36 \\
Colágeno & 2,65 & 0,41 & 1,6 & 0.55 & 4,19 \\
\hline
\end{tabular}




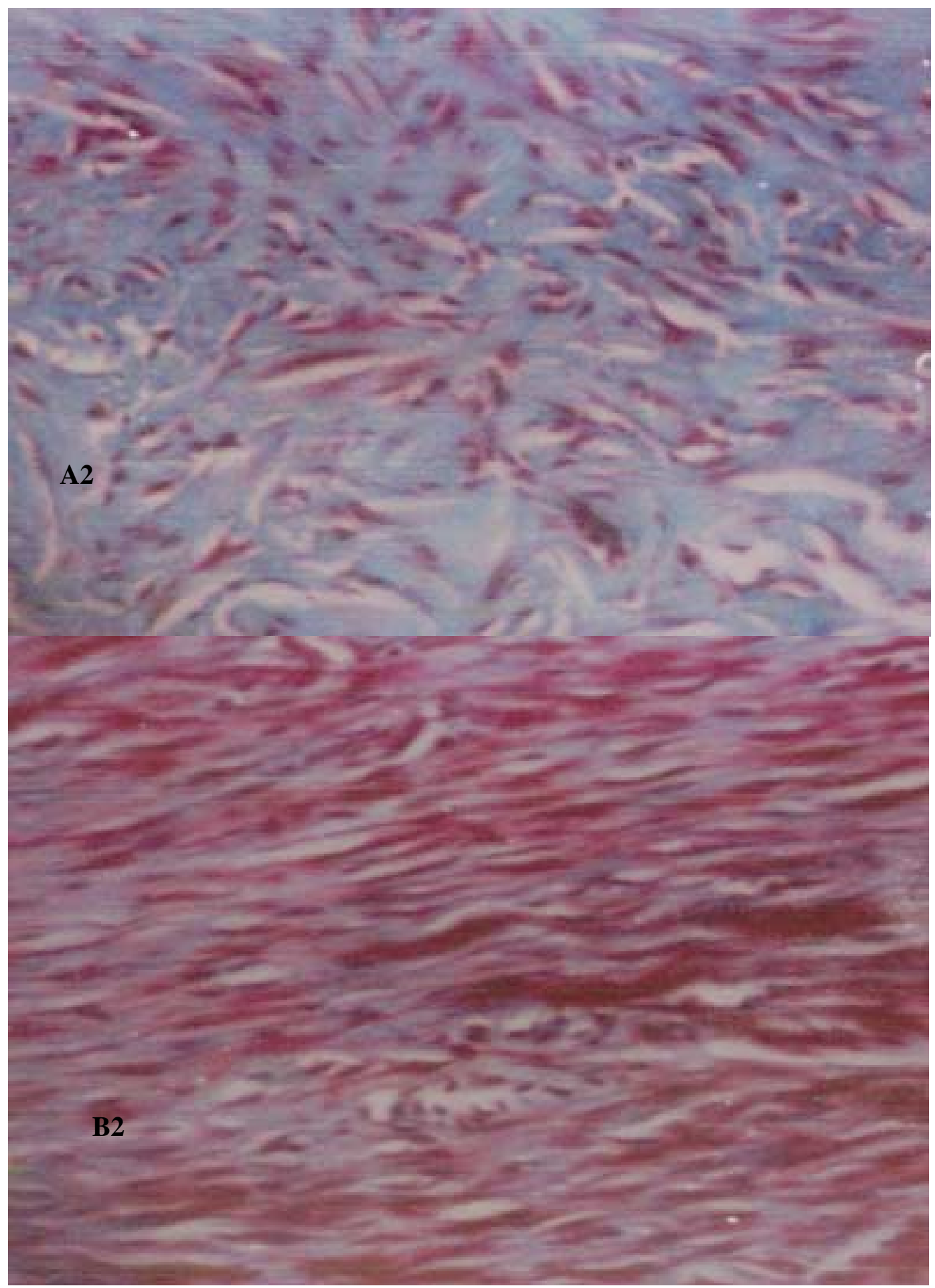

FIGURA - 07 Microscopia do tendão calcâneo de rato sacrificado no $15^{\circ} \mathrm{PO}$, corados por Tricrômico de Gomori. Corte longitudinal, mostrando maior presença de colágeno no grupo tratado. Aumento de 200x (A2= grupo tratamento e B2= grupo controle). 


\section{MÉDIAS ENTRE OS GRUPOS A2 X B2}

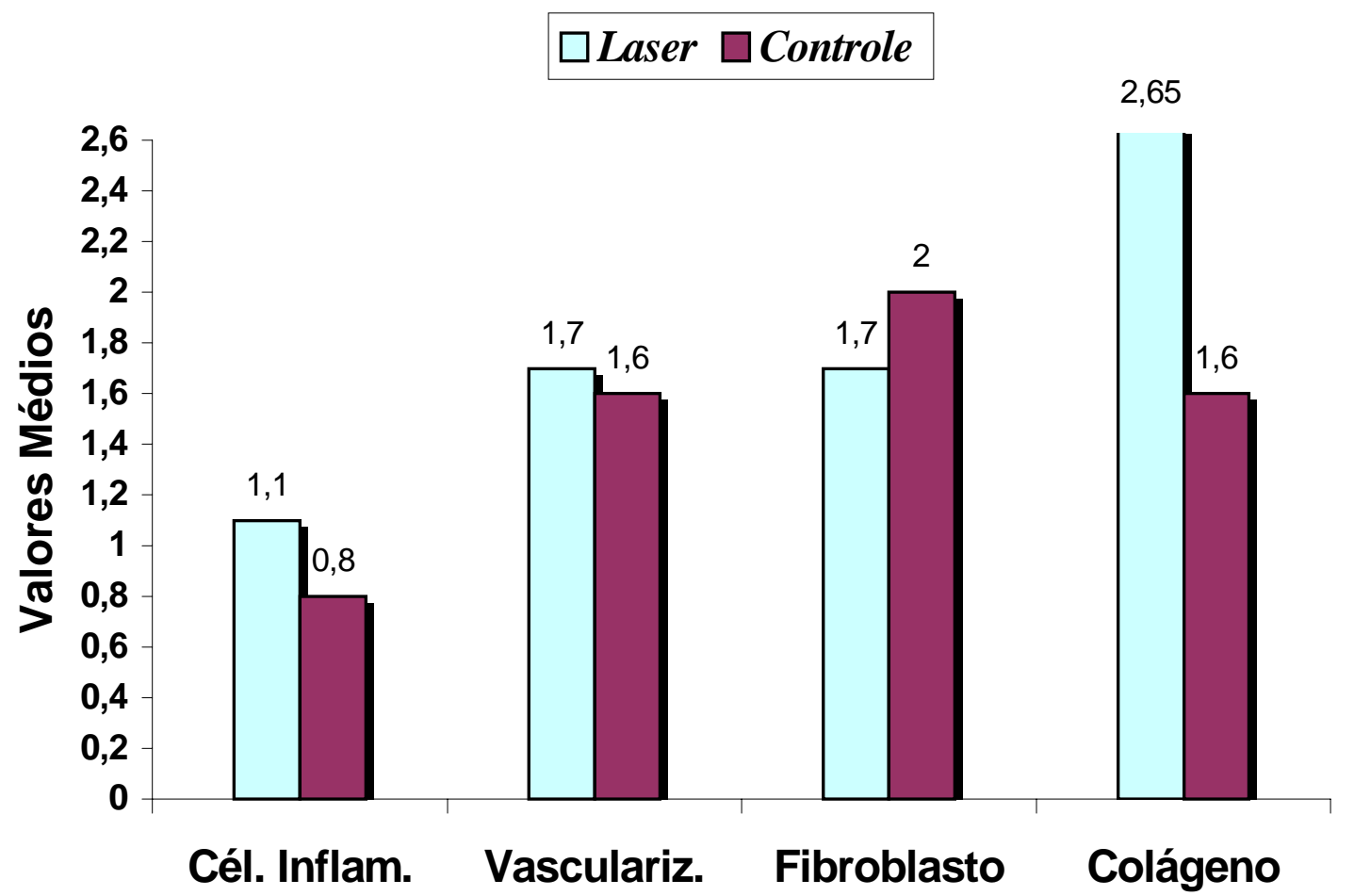

Figura 08 - Comparação das médias entre os grupos A2 e B2 - Histograma ilustrando o comportamento das variáveis no $15^{\circ} \mathrm{PO}$. Os resultados são obtidos através das médias de cada variável.

3.1.3 Grupo $\boldsymbol{A}_{1} \boldsymbol{x} \boldsymbol{A}_{2}$ ( tabela 04, figuras 09 e 10)

\subsubsection{Presença de Células Inflamatórias}

Houve diferença estatisticamente significante entre os grupos $(0.015<\mathrm{p}<0.02)$. Observou-se também, um índice maior de presença de células inflamatórias, em valores absolutos no grupo $\mathrm{A}_{2}$. 


\subsubsection{Vascularização}

Houve diferença estatística altamente significante entre os grupos $(\mathrm{p}<0.0005)$. Em valores absolutos, o grupo $\mathrm{A}_{2}$ tem grau de vascularização maior.

\subsubsection{Presença de Fibroblasto}

Houve diferença estatística muito significante entre os grupos $(0.0025<\mathrm{p}<0.005)$. Em valores absolutos, observa-se maior presença de fibroblasto no grupo $A_{1}$.

\subsubsection{Presença de Colágeno}

Não houve diferença estatisticamente significante entre os grupos $(0.15<\mathrm{p}<0.2)$. Observou-se porém, um índice maior de presença de colágeno, em valores absolutos no grupo $\mathrm{A}_{2}$.

Tabela 04 - Resultados das médias nos grupos com exposição ao laser.

\begin{tabular}{|l|l|l|l|l|l|}
\hline \multicolumn{7}{|l|}{ Médias entre os grupos com exposição ao laser } \\
\hline$A_{1} x A_{2}$ & \multicolumn{2}{l|}{$8^{\circ} P O \quad n=10$} & \multicolumn{2}{l|}{$15^{\circ}$ PO $n=10$} & $p<0,05$ \\
\hline Laser & Média & $S$ & Média & $S$ & \multicolumn{1}{l|}{$c_{c}$} \\
\hline Células inflamatórias & 0,45 & 0,5 & 1,1 & 0,74 & 2,31 \\
Vascularização & 1 & 0,82 & 1,7 & 0,82 & 5,2 \\
Fibroblasto & 2,25 & 0,35 & 1,7 & 0,48 & 2,9 \\
Colágeno & 2,35 & 0,82 & 2,65 & 0,41 & 1,04 \\
\hline
\end{tabular}




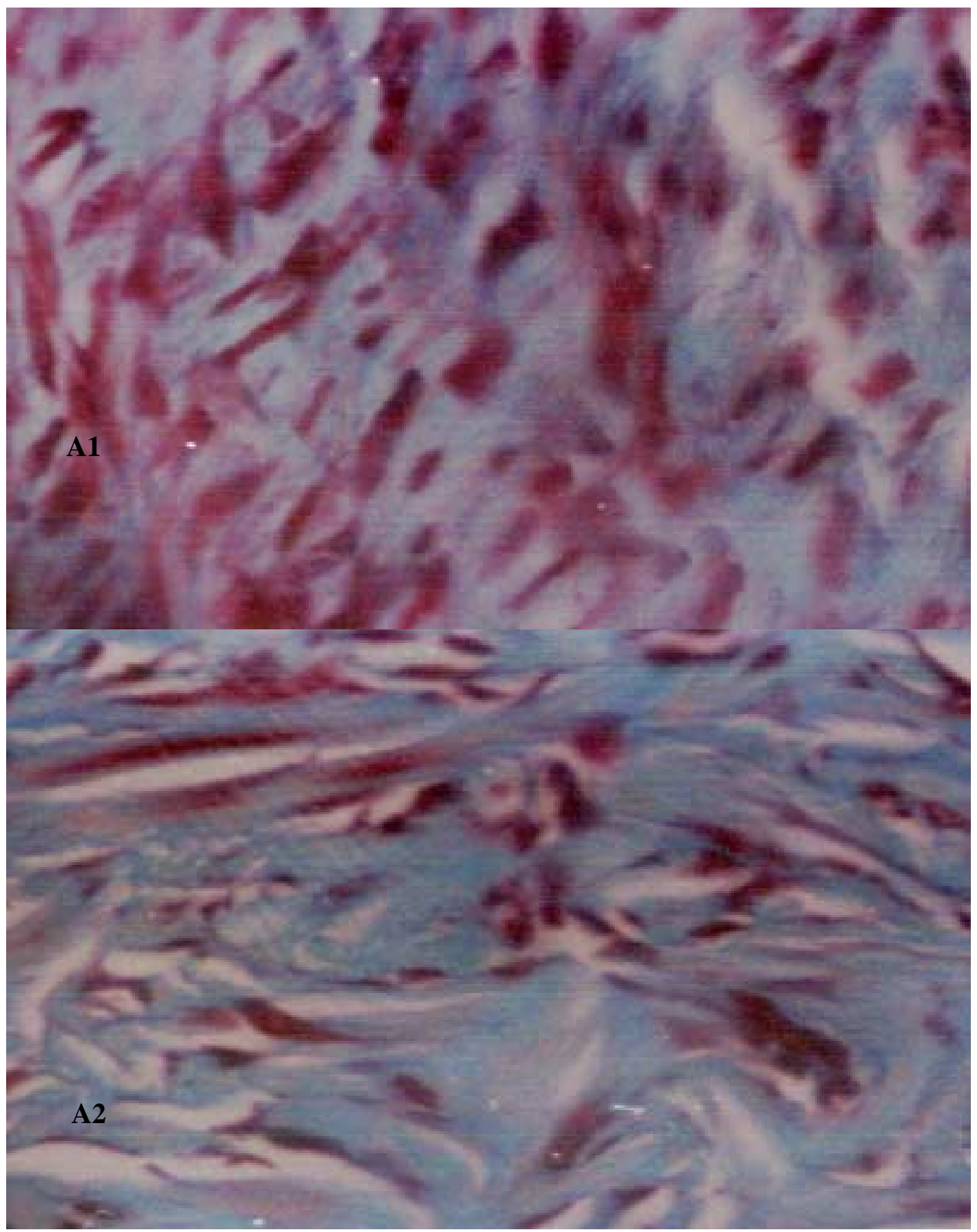

FIGURA - 09 Microscopia do tendão calcâneo de rato sacrificado no $8^{\circ}$ e no1 $5^{\circ} \mathrm{PO}$, corados por Tricrômico de Gomori. Corte longitudinal, mostrando maior presença de novos vasos na fase tardia do tratamento. Aumento de 400x ( $11=$ fase inicial e $\mathrm{A} 2=$ fase tardia). 


\section{MÉDIAS ENTRE OS GRUPOS A1 X A2}

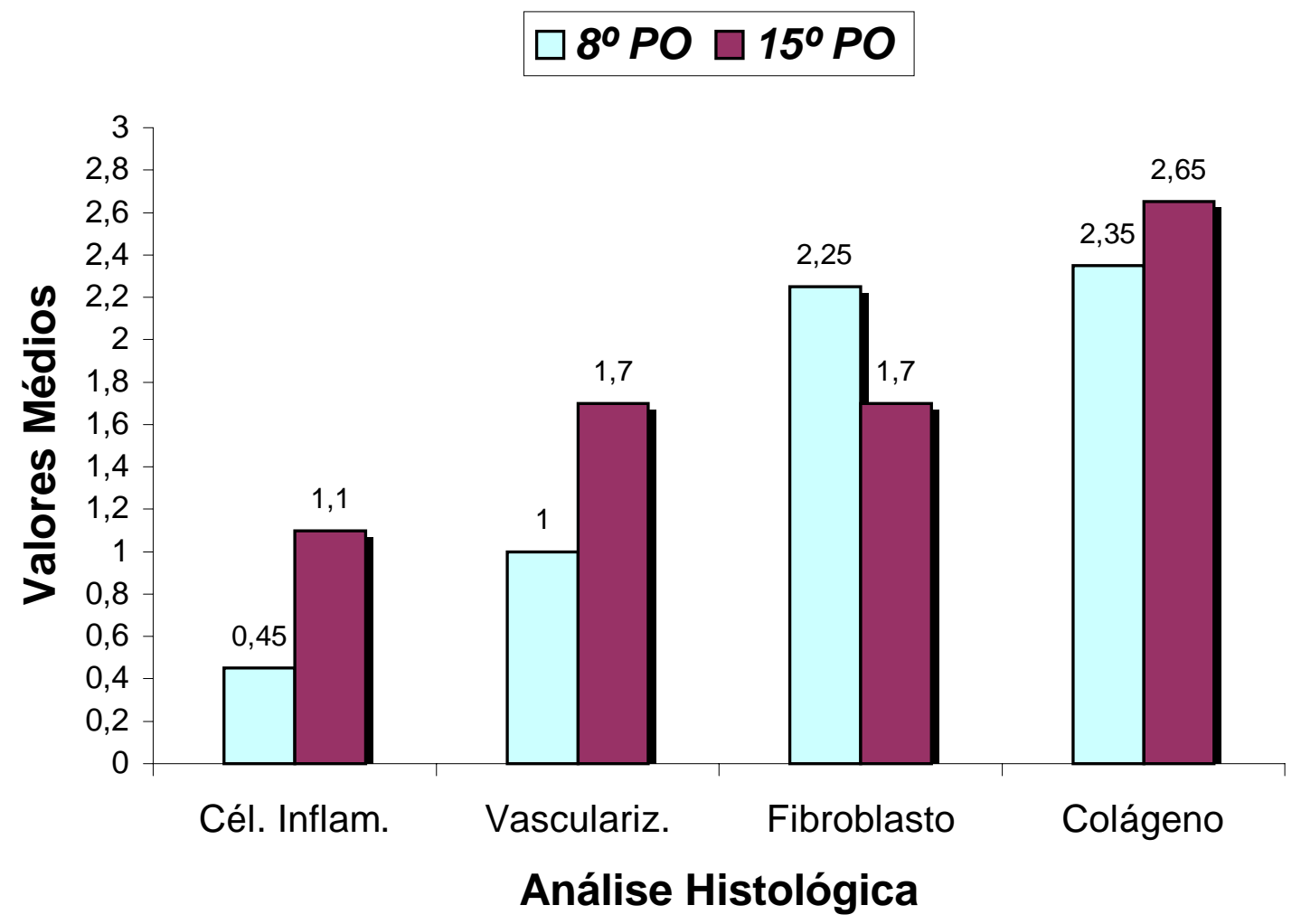

Figura 10 - Comparação das médias entre os grupos A1 e A2 - Histograma ilustrando o comportamento das variáveis no $8^{\circ}$ e $15^{\circ} \mathrm{PO}$. Os resultados são obtidos através das médias de cada variável.

3.1.4 Grupo $\boldsymbol{B}_{1} \boldsymbol{x} \boldsymbol{B}_{2}$ (tabela 05, figuras 11 e 12)

\subsubsection{Presença de Células Inflamatórias}

Não houve diferença estatisticamente significante entre os grupos $(0.05<\mathrm{p}<0.1)$. Observou-se porém, um índice maior de presença de células inflamatórias, em valores absolutos no grupo $\mathrm{B}_{1}$. 


\subsubsection{Vascularização}

Não houve diferença estatisticamente significante entre os grupos $(0.15<\mathrm{p}<0.2)$. Em valores absolutos, o grupo $\mathrm{B}_{2}$ tem grau de vascularização maior.

\subsubsection{Presença de Fibroblasto}

Não houve diferença estatisticamente significante entre os grupos $(0.05<\mathrm{p}<0.1)$. Em valores absolutos, observa-se maior presença de fibroblasto no grupo $\mathrm{B}_{1}$.

\subsubsection{Presença de Colágeno}

Não houve diferença estatisticamente significante entre os grupos $(0.2<\mathrm{p}<0.3)$. Observou-se porém, um índice maior de presença de colágeno, em valores absolutos no grupo $\mathrm{B}_{2}$.

Tabela 05 - Resultados das médias nos grupos controle.

\begin{tabular}{|l|l|l|l|l|l|}
\hline \multicolumn{7}{|l|}{ Médias entre os grupos controle } \\
\hline$B_{1} x B_{2}$ & \multicolumn{2}{l|}{$8^{\circ} P O \quad n=5$} & \multicolumn{2}{l|}{$15^{\circ} P O \quad n=5$} & $p<0,05$ \\
\hline Controle & Média & $S$ & Média & $S$ & $t_{c}$ \\
\hline Células inflamatórias & 1,2 & 0,45 & 0,8 & 0,45 & 1,41 \\
Vascularização & 1 & 1,22 & 1,6 & 0,55 & 1 \\
Fibroblasto & 2,3 & 0,45 & 2 & 0 & 1,5 \\
Colágeno & 1,4 & 0.55 & 1,6 & 0.55 & 0,58 \\
\hline
\end{tabular}




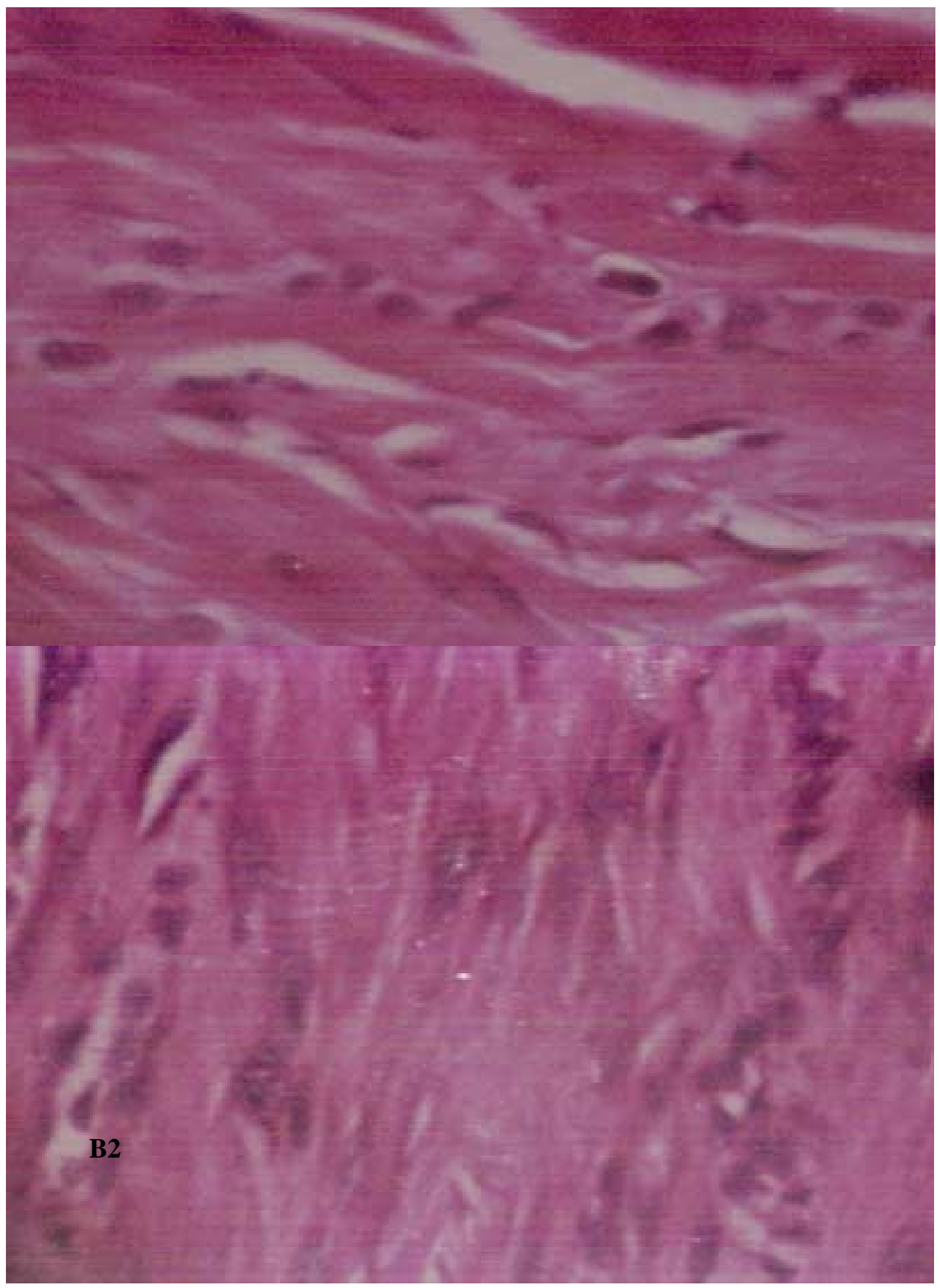

FIGURA - 11 Microscopia do tendão calcâneo de rato sacrificado no $8^{\circ}$ e no15 $5^{\circ} \mathrm{PO}$, corados pela Hematoxilina-Eosina. Corte longitudinal, mostrando a semelhança das fases inicial e tardia do grupo controle. Aumento de 400x (B1= fase inicial e B2= fase tardia). 


\section{MÉDIAS ENTRE OS GRUPOS B1 X B2}

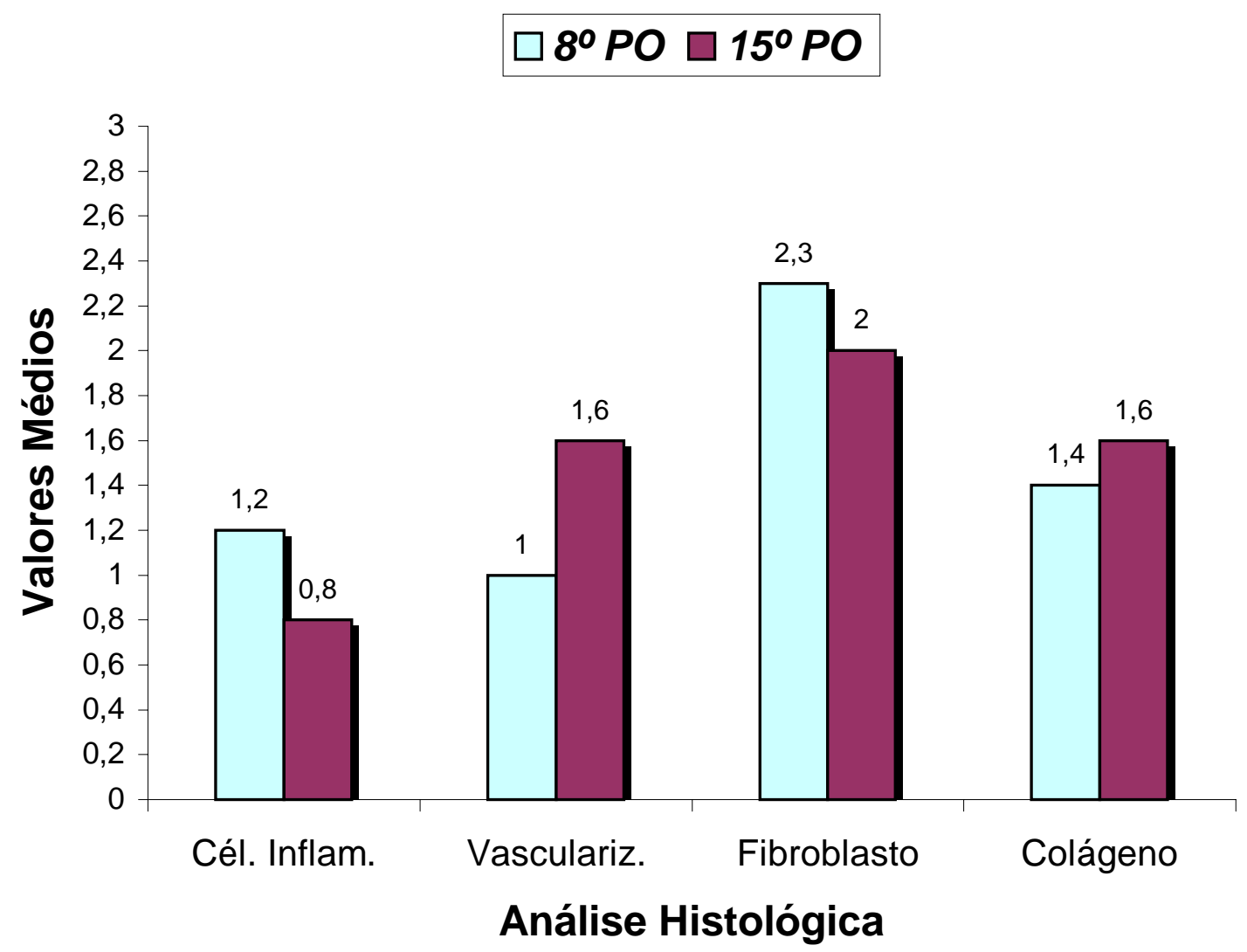

Figura 12 - Comparação das médias entre os grupos B1 e B2 - Histograma ilustrando o comportamento das variáveis no $8^{\circ}$ e $15^{\circ} \mathrm{PO}$. Os resultados são obtidos através das médias de cada variável. 


\subsection{OUTROS DADOS ENCONTRADOS}

\subsubsection{Presença de Células Gigantes}

Foi encontrado células gigantes multinucleadas, em duas lâminas: no animal 10 grupo $A_{1}$ e no animal 22 grupo $B_{1}$.

\subsubsection{Presença de Metaplasia Cartilaginosa}

Foi encontrado metaplasia cartilaginosa, em duas lâminas: no animal 15 grupo $\mathrm{A}_{2} \mathrm{e}$ no animal 40 grupo $\mathrm{B}_{2}$.

\subsubsection{Ausência de Necrose elou Calcificações}

Tentamos também observar o grau de necrose e/ou microcalcificações nas lâminas, porém estas não foram encontradas. 


\section{DISCUSSÃO}

Na literatura, encontramos muitos autores, que estudaram a cicatrização tendinosa de Achiles em animais, visando elucidar através dos vários tipos de tratamento, a reparação tecidual neste tipo específico de tendão (ENWEMEKA, 1991; ENWEMEKA, 1992; GUM et al, 1997; KUSCHNER et al, 1991; MURRELL et al, 1993; MURRELL et al, 1994; REDDY et al, 1998a; THEMANN et al, 1995; THEMANN et al, 1999). Entretanto, a maioria relata a necessidade de mais estudos para se obter dados mais conclusivos.

É importante ressaltar, que o interesse deste estudo é a observação das alterações causadas, pela aplicação do laser de baixa intensidade, no processo de reparação do tendão calcâneo em ratos.

A ação do laser de baixa intensidade na cicatrização tendinosa, foi estudada por autores que obtiveram resultados satisfatórios (REDDY et al, 1998; GUM et al, 1997). Porém encontramos dificuldades, para obter dados mais conclusivos na literatura, a respeito do laser na cicatrização tendinosa.

Decidimos escolher o rato, porque oferece facilidade no manuseio para realização da lesão, aplicação do laser, e de não necessitar obrigatoriamente de sutura e/ou imobilização, para a reparação de seu tendão calcâneo após uma lesão (MURRELL et al, 1993). 
A técnica cirúrgica de tenotomia calcaneana utilizada, foi de fácil execução e isenta de complicações durante o trans-operatório.

O laser AsGa $904 \mathrm{~nm}$ foi escolhido porque além de possuir um maior poder de penetração, em torno de 1,4 milímetros $(\mathrm{mm})$, o seu tamanho é reduzido, facilitando o manuseio, o custo do aparelho é menor (em relação aos outros presentes no mercado), ele é seguro e de simples aplicação (KOLARI, 1985).

A dose de $4 \mathrm{~J} / \mathrm{cm}^{2}$ foi utilizada por estar na faixa 3 à $6 \mathrm{~J} / \mathrm{cm}^{2}$, que é responsável pelo efeito cicatrizante (COLLS, 1984) além disso, outros autores já utilizaram esta dose (KANA et al, 1981; SCHMITT et al, 1993; TATARUNAS et al, 1998).

Durante irradiação, a caneta do aparelho foi posicionada a um ângulo de $90^{\circ}$, em relação ao tendão do animal, procurando portanto, diminuir o índice de dispersão das ondas eletromagnéticas (VEÇOSO, 1993). A ponta da caneta esteve em contado direto com a pele, no sítio da lesão.

A aplicação do laser foi sempre realizada 24 horas após a lesão, com a intenção de iniciar o tratamento na fase aguda de cicatrização, portanto observando os efeitos do laser AsGa nos eventos primários do reparo tendinoso.

No grupo tratado, houve radiação na fase aguda pelo período de sete dias consecutivos (10 animais) e manteve-se por mais sete dias, também consecutivos (outros 10 animais) conforme a tabela 1. O tempo para intervenção laserterápica, foi realizado considerando os eventos celulares e extracelulares, bem como as alterações ultra-estruturais do estágio inicial e tardio do processo de reparo (ENWEMEKA, 1989; GIGANTE et al, 1996).

Optamos em sacrificar os animais, 24 horas após a última aplicação de laser, portanto $8^{\circ}$ dia de pós-operatório (para analisar a fase inicial) e $15^{\circ}$ dia pós-operatório (para analisar a fase tardia do processo de reparação tendinosa).

Houve diferença estatística muito significante, no contraste de médias da presença de células inflamatórias, entre os grupos controle $\left(B_{1}\right)$ e tratamento $\left(A_{1}\right)$ na fase inicial de 
reparo, prevalecendo uma maior quantidade de células inflamatórias no subgrupo $B_{1}$. Na fase tardia não houve diferença estatística significante, entretanto em valores absolutos no subgrupo $A_{2}$, verificou-se um índice maior de presença de células inflamatórias.

Verificamos também, diferença estatística significante no contraste de médias entre fase inicial $\left(A_{1}\right)$ e tardia $\left(A_{2}\right)$ de tratamento, prevaleceu um índice maior de presença de células inflamatórias no subgrupo $\mathrm{A}_{2}$. No contraste de médias entre fase inicial $\left(\mathrm{B}_{1}\right)$ e tardia $\left(B_{2}\right)$ do controle, não houve diferença estatística significante, porém em valores absolutos, observou-se um índice maior de presença de células inflamatórias no subgrupo $\mathrm{B}_{1}$.

TATARUNAS et al (1998) também encontraram em seu experimento, uma menor quantidade de infiltrado inflamatório, após a aplicação do laser. Outros autores relatam o efeito anti-inflamatório do laser, que encontramos ao menos na fase inicial da cicatrização (COLLS, 1984; VEÇOSO, 1993; BAXTER, 1998; SILVA et al, 1998).

No contraste de médias entre controle e tratamento na fase inicial e tardia, não houve diferença estatística significativa na neovascularização, com valores absolutos também iguais para $\mathrm{A}_{1}$ e $\mathrm{B}_{1}$, e $\mathrm{A}_{2}$ com maior vascularização do que $\mathrm{B}_{2}$.

Comparou-se o grupo tratamento na fase inicial e tardia com relação a neovascularização, onde observou-se diferença estatística altamente significativa com prevalência de maior grau de vascularização no subgrupo $A_{2}$. Nos subgrupos controle, não houve diferença estatística significativa, entretanto observou-se maior grau de vascularização no subgrupo $\mathrm{B}_{2}$.

BIBIKOVA et al (1994) demonstraram que o laser, promove a formação de novos vasos a partir dos pré-existentes no sítio da lesão, porém há muitas variações em relação ao nosso experimento, como por exemplo a dose utilizada, o tipo de laser, o animal e o tipo de tecido usado. É importante ressaltar, que outros autores concordam com este efeito do laser

\section{(GONZÁLEZ \& CRUAÑAS, 1988; HERRERO, 1988).}

Na comparação entre controle e tratamento, com relação a presença de fibroblastos na fase inicial e tardia não houve diferença estatisticamente significante. Entretanto, houve 
uma pequena diferença em valores absolutos, com maior presença de fibroblastos nos subgrupos $\mathrm{B}_{1}$ e $\mathrm{B}_{2}$.

Em contraste, houve diferença estatística muito significante, comparando-se a fase inicial e tardia do tratamento, com prevalência de maior quantidade de fibroblastos no subgrupo $\mathrm{A}_{1}$.

Já no grupo controle não houve diferença estatística significante, porém houve diferença em valores absolutos, sendo que, o subgrupo $B_{1}$ com maior presença de fibroblastos.

HERRERO (1988) afirma que o laser promove a multiplicação dos fibroblastos, o que no entanto não foi demonstrado em nosso experimento. Outros autores, relatam a maior presença de fibroblastos, na fase inicial do processo de reparo (CURRIER \& NELSON, 1992; BAXTER, 1994; GIGANTE et al, 1996; COTRAN et al., 2000).

Com relação a presença de fibras de colágeno, houve diferença estatisticamente significante entre os grupos controle e tratamento na fase inicial de reparo. Também houve diferença estatística altamente significante, entre os grupos controle e tratamento na fase tardia de reparo. Em ambos os casos, fase inicial e tardia, houve prevalência de presença de fibras colágenas no grupo tratado.

Na comparação do grupo tratamento, entre fase inicial e tardia, não houve diferença estatisticamente significante. Isto ocorreu também na comparação do grupo controle entre fase inicial e tardia. Em ambos os casos, houve aumento de colágeno na fase tardia em valores absolutos.

REDDY et al. (1998a) concluíram que o laser estimula a cura do tendão, através da produção aumentada de colágeno pela matriz colagenosa, porém a dose utilizado foi menor, comparada com o nosso experimento. Vários outros autores concordam que o laser promove a deposição acelerada de fibras de colágeno na zona de lesão (GONZÁLEZ \& CRUAÑAS, 1988; HERRERO, 1988; BAXTER, 1994). 
Foi encontrado também, a presença de células gigantes multinucleadas em dois animais (rato 10 e 22) isto se deve provavelmente pela fusão de macrófagos, transformando-se em células epitelióides, que são o resultado de uma inflamação persistente (COTRAN et al., 2000). A inflamação persistente pode ser explicada pela descarga de peso no membro lesado, já que os animais não eram imobilizados.

Encontramos ainda, a presença de metaplasia cartilaginosa em dois animais (rato $15 \mathrm{e}$ 40) um no grupo controle e outro no grupo tratamento, não encontramos na literatura nenhuma explicação para este fato.

Assim, pode-se ver que este estudo fornece evidências do efeito benéfico da irradiação por laser, com relação a cicatrização do tendão calcâneo em ratos. Embora os estudos em animais, como os delineados acima, efetivamente avancem um pouco e diminuam a lacuna existente entre a pesquisa e a prática clínica, ainda restam alguns questionamentos a serem respondidos, tais como: dose ideal para um determinado tratamento; tipo de laser a ser utilizado; fase da inflamação ideal para a intervenção laserterápica e outros.

Este estudo sugere que o laser terapêutico é benéfico na cicatrização tendinosa, demonstrando evidências de uma diminuição no tempo de cicatrização e conseqüentemente, um retorno mais rápido à funcionalidade do tecido lesado. 


\section{CONCLUSÃO}

Baseado nos resultados encontrados, o laser AsGa 904nm, quando utilizado na dose de $4 \mathrm{~J} / \mathrm{cm}^{2}$, promove a deposição de colágeno no sítio da lesão na fase inicial e tardia, também minimiza a presença de células inflamatórias na zona de lesão na fase inicial da cicatrização do tendão calcâneo de ratos. 
Anexo A - Valores individuais de cada animal sacrificado no $8^{\circ}$ dia PO.

Grupo $\mathbf{A}_{1}$

\begin{tabular}{|c|c|c|c|c|}
\hline $\begin{array}{c}7 \text { dias c/ laser } \\
\text { Animal no }\end{array}$ & $\begin{array}{c}\text { Células } \\
\text { Infamatórias }\end{array}$ & Vascularização & $\begin{array}{c}\text { Presença de } \\
\text { Fibroblastos }\end{array}$ & $\begin{array}{c}\text { Presença de } \\
\text { Colágeno }\end{array}$ \\
\hline 1 & F+ & N & +++ & ++ \\
\hline 2 & - & + & $++/+++$ & $++/++$ \\
\hline 3 & - & + & $++/+++$ & + \\
\hline 4 & - & + & ++ & + \\
\hline 5 & - & N & $++/+++$ & +++ \\
\hline 6 & - & ++ & ++ & ++ \\
\hline 7 & F+ & ++ & ++ & +++ \\
\hline 8 & D+ & N & ++ & +++ \\
\hline 9 & D-/+ & + & ++ & +++ \\
\hline $10^{*}$ & F+ & ++ & ++ & +++ \\
\hline
\end{tabular}

- =Ausente, $+=$ Leve, $++=$ Moderado, $+++=$ Acentuado, N=Normal, D=Difuso,

$\mathrm{F}=\mathrm{Focal}, *$ = Presença de Células Gigantes. 
Anexo B - Valores individuais de cada animal sacrificado no $8^{\circ}$ dia PO.

\section{Grupo B 1}

\begin{tabular}{|c|c|c|c|c|}
\hline $\begin{array}{c}7 \text { dias s/ laser } \\
\text { Animal no }\end{array}$ & $\begin{array}{c}\text { Células } \\
\text { Infamatórias }\end{array}$ & Vascularização & $\begin{array}{c}\text { Presença de } \\
\text { Fibroblastos }\end{array}$ & $\begin{array}{c}\text { Presença de } \\
\text { Colágeno }\end{array}$ \\
\hline 21 & F+ & +++ & +++ & ++ \\
\hline $22^{*}$ & F+ & + & ++ & ++ \\
\hline 25 & F+ & N & $++/+++$ & + \\
\hline 28 & D++ & + & ++ & + \\
\hline 29 & F+ & N & ++ & + \\
\hline
\end{tabular}

- =Ausente, +=Leve, $++=$ Moderado, $+++=$ Acentuado, N=Normal, D=Difuso, $\mathrm{F}=\mathrm{Focal}, *=$ Presença de Células Gigantes. 
Anexo C - Valores individuais de cada animal sacrificado no $15^{\circ}$ dia PO.

Grupo $\mathbf{A}_{2}$

\begin{tabular}{|c|c|c|c|c|}
\hline $\begin{array}{c}\text { 14 dias c/ laser } \\
\text { Animal n }\end{array}$ & $\begin{array}{c}\text { Células } \\
\text { Infamatórias }\end{array}$ & Vascularização & $\begin{array}{c}\text { Presença de } \\
\text { Fibroblastos }\end{array}$ & $\begin{array}{c}\text { Presença de } \\
\text { Colágeno }\end{array}$ \\
\hline 11 & F+ & + & + & +++ \\
\hline 12 & F+ & ++ & ++ & ++ \\
\hline 13 & D+++ & +++ & ++ & $++/+++$ \\
\hline 14 & F+ & ++ & ++ & ++ \\
\hline $15 \#$ & - & + & + & $++/+++$ \\
\hline 16 & F+ & ++ & + & $++/+++$ \\
\hline 17 & F+ & N & ++ & +++ \\
\hline 18 & F+ & ++ & ++ & +++ \\
\hline 19 & F+ & ++ & ++ & +++ \\
\hline 20 & F+ & ++ & ++ & +++ \\
\hline
\end{tabular}

- =Ausente, $+=$ Leve, ++=Moderado, $+++=$ Acentuado, $\mathrm{N}=$ Normal, $\mathrm{D}=$ Difuso, $\mathrm{F}=$ Focal, $*$ = Presença de Células Gigantes, \# = Metaplasia Cartilaginosa. 
Anexo D - Valores individuais de cada animal sacrificado no $15^{\circ}$ dia PO.

Grupo $\mathbf{B}_{2}$

\begin{tabular}{|c|c|c|c|c|}
\hline $\begin{array}{c}\text { 14 dias S/ laser } \\
\text { Animal no }\end{array}$ & $\begin{array}{c}\text { Células } \\
\text { Infamatórias }\end{array}$ & Vascularização & $\begin{array}{c}\text { Presença de } \\
\text { Fibroblastos }\end{array}$ & $\begin{array}{c}\text { Presença de } \\
\text { Colágeno }\end{array}$ \\
\hline 32 & F+ & + & ++ & ++ \\
\hline 33 & F+ & ++ & ++ & + \\
\hline 37 & F+ & + & ++ & ++ \\
\hline 39 & - & ++ & ++ & ++ \\
\hline $40 \#$ & F+ & ++ & ++ & + \\
\hline
\end{tabular}

- =Ausente, +=Leve, ++=Moderado, +++=Acentuado, N=Normal, D=Difuso, F=Focal, * = Presença de Células Gigantes, \# = Metaplasia Cartilaginosa. 
Anexo E - Tabela demonstrando as distribuições de $t$ retirada de JEKEL et al. (1999).

TABELA C Pontos Percentuais Superiores para Distribuipoes $t$

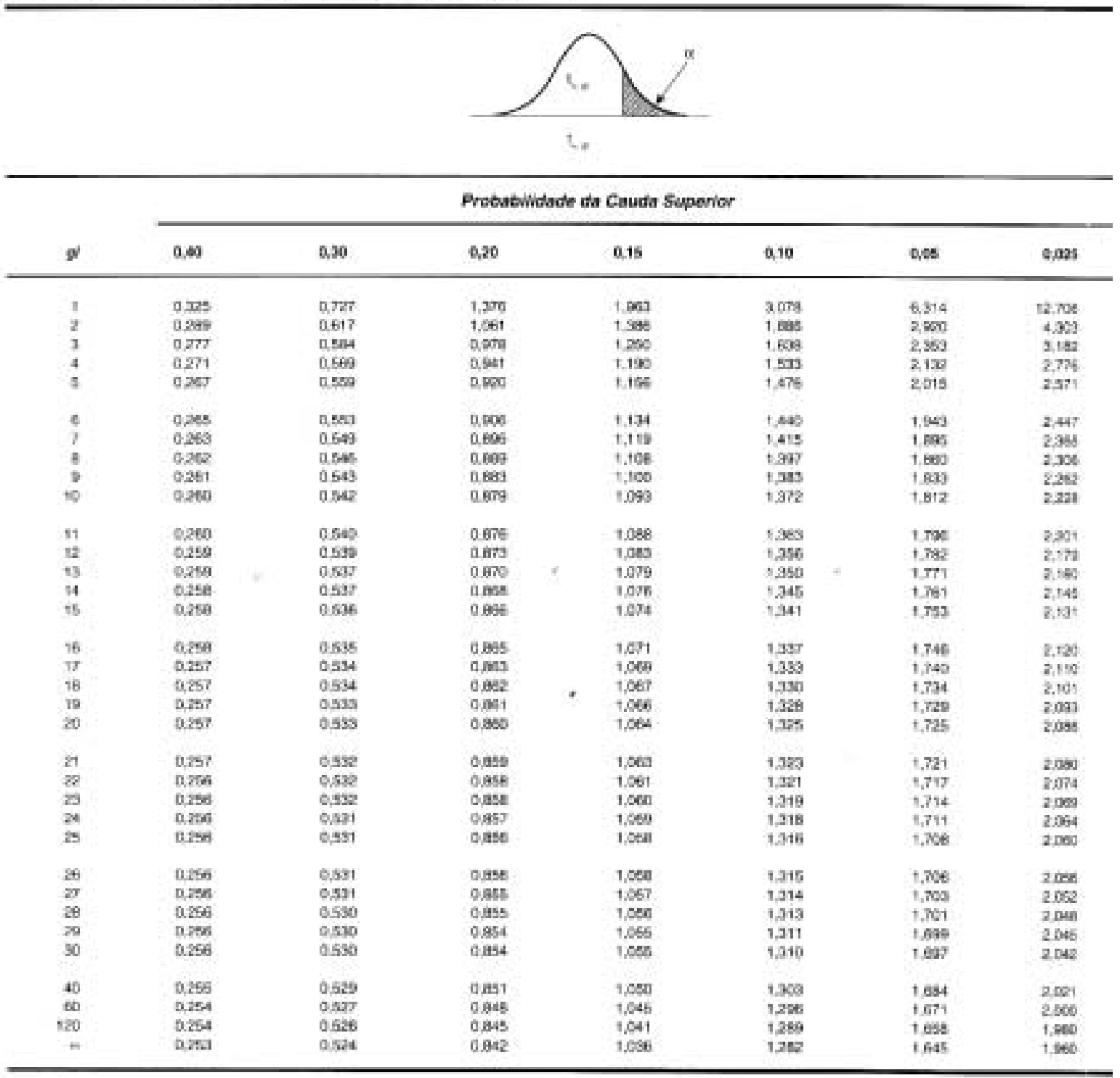


Anexo F - Tabela demonstrando as distribuições de $t$ continuação, retirada de JEKEL et al. (1999).

TABELA C Pontos Percentuais Superiores para Distribuiçbes t (Continuaçajo)

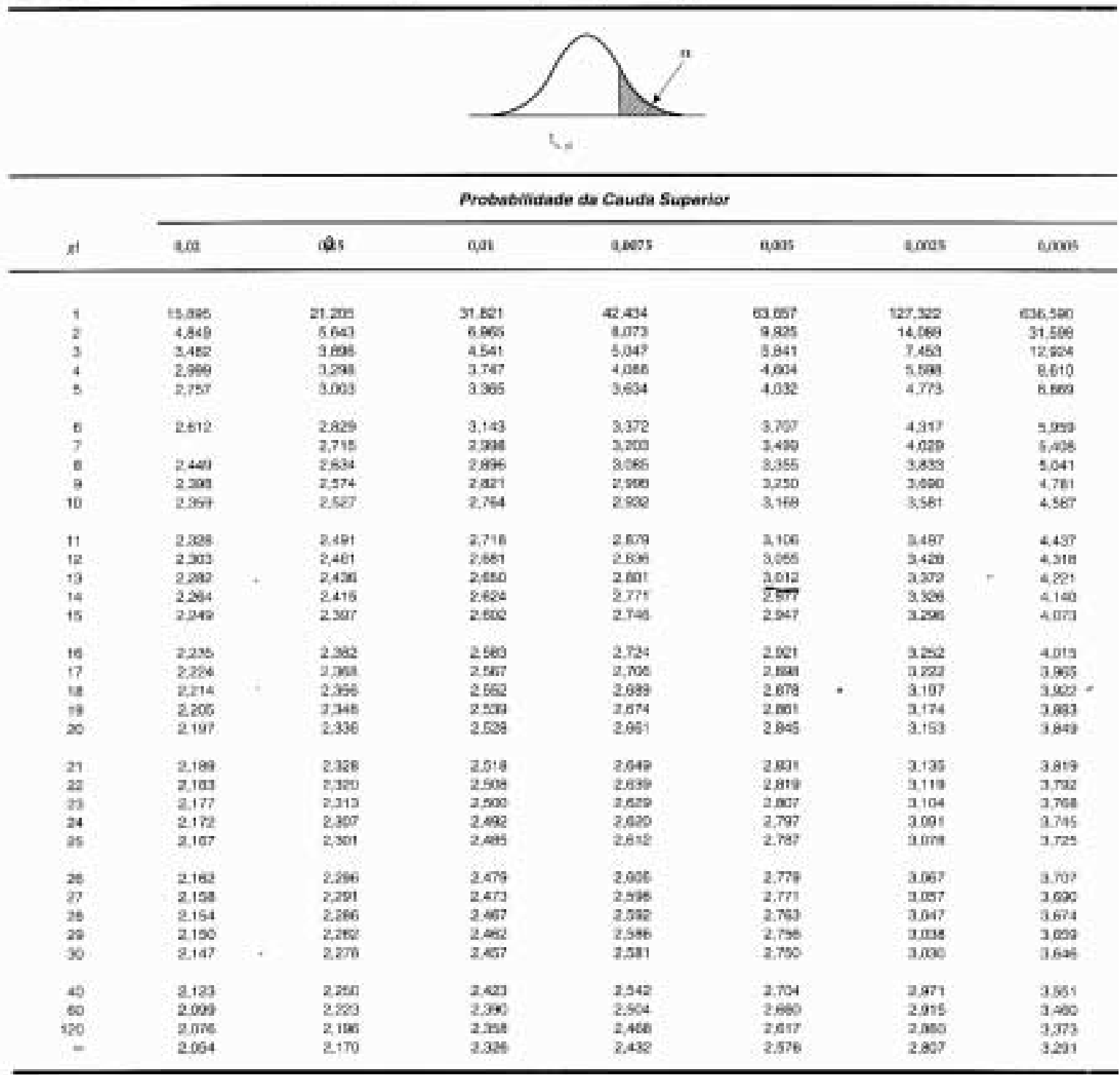




\section{REFERÊNCIAS BIBLIOGRÁFICAS}

ALBERGEL, R.P. et al. (1984). Biostimulation of procollagen production by low energy lasers in human skin fibroblast cultures. J. Invest. Dermatol., v. 82, p. 395-402.

ANNEROTH, G. et al. (1988). The effect of low energy infra-red laser radiation on wound healing in rats. British Journal of Oral and Maxilofacial Surgery, v. 26, p. 12-17.

BAXTER, D.G. (1994). Therapeutic Lasers: Theory e and Practice. New York, Churchill Livingstone.

BAXTER, D. (1998).Laserterapia de Baixa Intensidade. In: KITCHEN, S.; BAZIN, S. Eletroterapia de Clayton. São Paulo, Manole. Cap. 13, p. 191-210.

BIBIKOVA, A.; BELKIN, V.; ORON, U. (1994). Enhancement of angiogenesis in regenerating gastrocnemius muscle of the toad (Bufo viridis) by low-energy laser irradiation. Anatomy and Embryology, v. 190, p. 597-602.

CARLSTEDT, C.A. (1987). Mechanical and chemical factors in tendon healing: Efects of indomethacin and surgery in the rabbit. Acta Orthopaedica Scandinavica, v.58, n.224, p.1-75.

COLLS, J. (1984). La Terapia Laser Hoy. Barcelona, Centro de Documentación Láser de Meditec. 
COLLS, J. (1988). Enfoque conceptual de las radiaciones eletromagnéticas. Boletim do Centro de Documentación Láser de Meditec, n. 15-16, p. 1-5.

COTRAN, R.S.; KUMAR, V.; ROBBINS, S.L. (2000). Robbins: Patologia Estrutural e Funcional. Rio de Janeiro, Guanabara Koogan. Cap. 3, p. 44 -77: Inflamação e Reparação.

CURRIER, D.P.; NELSON, R.M. (1992). Dynamics of Human Biologic Tissue. In: ENWEMEKA, C.S.; SPIELHOLZ, N.I. Modulation of Tendon Grouth and Regeneration by Eletrical Fields and Currents. Philadelphia, F. A . Davis Company, cap. 3, p.231-254.

DÂNGELO, J.G.; FATTINI, C.A. (2001). Anatomia Humana Básica. São Paulo, Atheneu. Cap.4, p.44: Sistema Muscular.

ENWEMEKA, C.S. (1989). Inflammation, cellularity, and fibrillogenesis in regenerating tendon: implications for tendon rehabilitation. Physical Therapy, v. 69, n.10, p. 816-825, oct.

ENWEMEKA, C.S. (1991). Membrane-bound intracellular collagen fibrils in fibroblasts and myofibroblasts of regenerating rabbit calcaneal tendons. Tissue and Cell, n. 23, v. 2, p. 173-190.

ENWEMEKA, C.S. (1992). Functional loading augments the initial tensile strength and energy absorption capacity of regenerating rabbit Achilles tendons. Am. J. Phys. Med. Rehabil., v. 71, p. 31-38.

GIGANTE, A. et al. (1996). Fibrillogenesis in tendon healing: an experimental study. $J$. Biol. Res. - Boll Soc. It. Biol. Sper. Napoli, v.7-8, n.72, p.203-210.

GONZÁLEZ, M.V.; CRUAÑAS, J.C. (1988). Comportamiento de la luz en la interaccion con los tejidos, en especial el laser de baja potencia. Boletim do Centro de Documentación Láser de Meditec, n. 15-16, p. 6-21.

GRECO, M. et al. (1989). Increase in RNA and protein synthesis by mitochondria irradiated with Helium - Néon laser. Biochemical and Biophycal Research Communications, v. 163, n. 3, p. 1428-1434, Sept. 
GUM, S.L. et al. (1997). Combined ultrasound, electrical stimulation and laser promote collagen synthesis with moderate changes in tendon biomechanics. Am. J. Phys. Med. Rehabil., v. 76, p.288-296.

HALLIDAY, D.; RESNICK, R. (1981). Física. Rio de Janeiro, Livros Técnicos e Científicos Editora. V. 2, Cap. 49, p. 275-276:

HERRERO, C. (1988). Los efectos terapeuticos. Boletim do Centro de Documentación Láser de Meditec, n. 15-16, p. 22-26.

HERRERO, C.; COLLS, J.; VÉLEZ, M. (1988). Las dosimetrias en equipos de baja potencia. Boletim do Centro de Documentación Láser de Meditec, n. 15-16, p. 31-36.

HOLlENSHEAD, W. H. (1980). Livro Texto de Anatomia Humana. São Paulo, Harbra Harper \& Row do Brasil. Cap. 3, p. 18: Os Tecidos Cojuntivos.

JEKEL, J.F.; ELMORE, J.G.; KATZ, D.L. (1999). Epidemiologia, Bioestatística e Medicina Preventiva. Porto Alegre, Artmed. Parte II, p. 99-200: Bioestatística.

JUNQUEIRA, L.C.; CARNEIRO, J. (1995). Histologia Básica. Rio de Janeiro, Guanabara Koogan. Cap. 5, p. 69-78: Tecido Conjuntivo.

KANA, J.S. et al. (1981). Effect of low-power density laser radiation on healing of open skin wounds in rats. Arch. Surg., v. 116, p. 293-296.

KASTELIC, J.; GALESKI, A.; BAER, E. (1978). The multicomposite structure of tendon. Connective Tissue Research, v.6, n.1, p. 11-23.

KARU, T.; PYATIBRAT, L.; KALENDO, G. (1995). Irradiation with He-Ne laser increase ATP level in cells cultivated in vitro. Journal of Photochemistry and Photobiology B: Biology, v. 27, p. 219-223.

KOLARI, P.J. (1985). Penetration of unfocused laser light into the skin. Arch. Dermatol., v.277. p. 342-344.

KUSCHNER, S.H. et al. (1991). A comparison of the healing properties of rabbit achilles tendon injuries at different levels. Clinical Orthopaedics and Related Research, n. 272, p. $268-273$. 
LEHMANN, J.F.; LATEUR, B.J. (1994). Tratado de Medicina Física e Reabilitação de KRUSEN. Rio de Janeiro, Manole. Cap.13, p.277-356: Diatermia e Calor Superficial, Laser e Crioterapia.

LONGO, L. et al. ( 1987). Effect of diodes-laser silver arsenide-aluminium (Ga-Al-As) 904 $\mathrm{nm}$ on healing of experimental wounds. Lasers in Surgery and Medicine, v. 7, p. 444447.

MELLO, M.L. et al. (1975). Changes in macromolecular orientational on collagen fibers during the process of tendon repair in the rat. Ann. Histochim, v. 20 , p. $145-152$.

MURRELL, G.A.C. et al. (1993). Achilles tendon injuries: a comparison of surgical repair versus no repair in a rat model. Foot \& Ankle, v. 14, n.7, p. 400-406, sept.

MURRELL, G.A.C. et al. (1994). Effects of immobilization on Achilles tendon healing in a rat model. Journal of Orthopaedic Research, v.12, n.4, p. 582-591.

NEMTSEV, I.Z.; LAPSHIN, V.P. (1997). The mechanism of action of low intensity laser radiation. Vopr Kurortol Fisioter Lech Fiz Kult, v. 1, n. 1, p. 22-24, jan-fev.

PASSARELLA, S. et al. (1988). Increase in the ADP/ATP exchange in rat liver mitochondria irradiated in vitro by Hélium - Neon laser. Biochemical and Biophysical Research Communications, v. 156, n. 2, p. 978-986, Oct.

REDDY, G.K.; STEHNO-BITTEL, L.; ENWEMEKA, C.S. (1998a). Laser photostimulation of collagen production in healing rabbit Achilles tendons. Lasers in Surgery and Medicine, v. 22, p. 281-287.

REDDY, G.K. et al. (1998b). Biochemistry and biomechanics of healing tendon: part II. effects of combined laser therapy and electrical stimulation. Medicine \& Science in Sports \& Exercise, v. 30, n. 6, p. 794-800.

SCHIMITT, I. et al. (1993). Os efeitos da radiação laser arseneto de gálio (AsGa) sobre a regeneração de tendões em cães. Braz. J. Vet. Res. Anim. Sci., v. 30, n. 2, p. 145-149.

SILVA, E.C.; FILHO, A.H.; MUSSKOPF, D.E. (1998). Radiação Laser. In: RODRIGUES, E.M. Manual de Recursos Terapêuticos. Rio de Janeiro, Revinter. Cap. 3, p. 17-35. 
STRICKLAND, J. W. (1989). Flexor tendon surgery. J. Hand Surgery, v. 14-b, p.261-272.

TATARUNAS, A.C.; MATERA, J.M.; DAGLI, M.L.Z. (1998). Estudo clinico e anatomopatológico da cicatrização cutânea no gato doméstico: utilização do laser de baixa potência GAAS (904 NM). Acta Cirúrgica Brasileira, v. 13, n. 2, p. 86-93.

THERMANN, H. et al. (1995). Die funktionelle behandlung der frischen achillessehnenruptur: eine experimentelle biomechanische untersuchung. Unfallchirurg, v. 98, p. 507-513.

THERMANN, H. et al. (1999). Die funktionelle behandlung der frischen achillessehnenruptur: eine histologische, immunhistologische und sonographische studie am tiermodell. Unfallchirurg, v. 102, p. 447-457.

TRIOLA, M.F. (2000). Introdução à Estatística. Rio de Janeiro LTC, $8^{\mathrm{a}}$ edição.

VEÇOSO, M.C. (1993). Laser em Fisioterapia. São Paulo, Lovise.

VIDAL, B. C.; CARVALHO, H. F. Agregational state an molecular order of tendons as a function of age. Matrix, v. 10, p. 48 - 57, 1990.

VILLARTA, R.; VIDAL, B.C. Anisotropic and biomechanical properties of tendons modified by exercise and denervation: aggregation and macromolecular order in collagen bundles. Matrix, v. 9, p.55 - 61, 1989. 